\title{
Aspectos demográficos de las provincias germanas en época romana
}

\author{
M. ${ }^{a}$ Remedios García MartíneZ*
}

\section{RESUMEN}

Los testimonios epigráficos de las provincias romanas de Germania Superior y Germania Inferior, sobre todo los epitafios, nos proporcionan la documentación demográfica relativa a la edad y a la origo. Se trata de ofrecer en este artículo una visión conjunta del ámbito demográfico en las provincias citadas estudiando la mortalidad y los movimientos migratorios. Al final del artículo se incluyen unas tablas de datos que recogen la información extraída de las fuentes epigráficas.

\section{ABSTRACT}

The epigraphic evidence of the Roman Provinces of Upper Germany and Lower Germany, specially the epitaph, gives us the demographic documentation regarding the age and the origo. This article tries to show a whole vision of the demographic field in the mentioned provinces by studying the mortality and the migratory movements. At the end of the article, some data charts are included, which contain the information taken from the epigraphic sources.

La mortalidad y los movimientos migratorios en las provincias germanas son estudiados a través de la epigrafía '. Las inscripciones fune-

* Universidad de Valladolid.

1 En las Tablas de Datos, que recogen la documentación de las inscripciones analizadas, se utilizan abreviaturas en el apartado del status: $A=$ Ancilla,$D=$ Dominus, $E=$ Ecuestre, $L=L i b e r t o$, 
rarias suelen mencionar la edad del difunto, y en ocasiones, también la origo, pues se quiere dejar constancia de que el fallecimiento se produjo lejos de la ciudad natal ${ }^{2}$. Somos conscientes de que las valoraciones acerca de la esperanza media de vida en época romana en las provincias de Germania Superior y Germania Inferior sólo tienen un carácter aproximativo, pues al tratarse de un estudio epigráfico no disponemos de la totalidad de datos demográficos de los individuos que murieron en dichas provincias ${ }^{3}$. No obstante, a pesar de este inconveniente, la documentación epigráfica analizada nos ha permitido extraer conclusiones interesantes.

En Germania Superior, en el ámbito demográfico de la edad, constatamos que las cotas más elevadas de mortalidad ocurren entre los 20 y los 50 años, con un mayor número de defunciones a los 40, 35, 30 y 20 años, de modo que sobrepasan la treintena de fallecimientos en cada una de estas edades, seguidas de cotas más inferiores que corresponden a los 45 años $(18 \mathrm{~m}),$.50 años $(17 \mathrm{~m}),$.37 años $(10 \mathrm{~m}$.) y 36 años $(9 \mathrm{~m}$.$) . En$ Germania Inferior, el mayor número de muertes se produce entre los $30 \mathrm{y}$ los 50 años, y en este intervalo de edad comprobamos que entre los $30 \mathrm{y}$ los 35 años, el índice de fallecimientos es áun más elevado, superando la decena de muestras para cada edad, seguidas de cotas más inferiores que se sitúan entre los 40 y 50 años, con siete muestras en cada caso, y los 45 años, con seis ejemplos. En ambas provincias germanas, en el resto de edades el número de defunciones es inferior a las cifras mencio-

$\mathrm{P}=$ Patrono, $\mathrm{V}=$ Verna; en el Lugar de hallazgo: $\mathrm{ALE}=$ Alemania, $\mathrm{AQ}=$ Aquisgrán, $\mathrm{BA}=\mathrm{Baden}$, $\mathrm{BAV}=$ Baviera, $\mathrm{COB}=$ Coblenza, $\mathrm{DU}=$ Düsseldorf, $\mathrm{FRA}=$ Francia, $\mathrm{GS}=$ Germania Superior, $\mathrm{HA}$ $=$ Hagenau, $\mathrm{NE}=$ Neuss, $\mathrm{NI}=$ Nimega, $\mathrm{PB}=$ Países Bajos, $\mathrm{SU}=$ Suiza, WE $=$ Westfalia, $\mathrm{WU}=$ Wütemberg; y en la Bibliografía: $\mathrm{AE}=$ L'Année Epigraphique, París, 1889-1992; $\mathrm{CIL}=$ Corpus Inscriptionum Latinarum, Vol. XIII y Suplemento; $\mathrm{N}=\mathrm{H}$. Nesselhauf, "Neue Inschriften aus dem römischen Germanien und den angrenzenden Gebieten», BRGK, 27, 1937, 51-134; $\mathrm{NL}=\mathrm{H}$. Nesselhauf \& H. Lieb, "Dritter Nachtrag zu CIL XIII. Inscrhiften aus den germanischen Provinzen und dem Treverergebiet", BRGK, 1959, 120-228; SCH = Schillenger, U, "Vierter Nachtrag zu CIL XIII und zweiter Nachtrag zu Fr. Vollmer, Inscriptiones Bavariae Romanae. Inscrhriften aus dem deutschen Anteil der germanischen Provinzen und des Treverergebietes sowie Rätiens und Noricums», BRGK, LVIII, 1977, 447-603.

2 En general, podemos afirmar que en aquellos casos en que el individuo alude al lugar de origen en su epitafio, es porque se encuentra alejado de su ciudad natal. Vid. Ma $R$. García Martínez, "Caracteres y significación socio-económica de los movimientos de población hispana hacia las provincias imperiales en época romana", HAnt, XV, 1991, 263-301.

3 En los epitafios estudiados, no todos ellos expresan la edad del difunto. Además, hay que tener en cuenta que todos los individuos no podian costearse una inscripción funeraria porque no disponían de suficientes recursos económicos. 
nadas anteriormente ${ }^{4}$. En cuanto al sexo de los individuos difuntos, evidenciamos tanto en Germania Superior como en Germania Inferior una mayor abundancia de defunciones de varones, que alcanzan un porcentaje superior al $90 \%$, respecto al total de individuos que indican la edad. Estas cifras tan reducidas de fallecimientos femeninos se encuentran en relación directa con la proporción total de mujeres, ya que en la inmensa mayoría de grupos gentilicios resulta bastante más inferior la tasa femenina que el porcentaje de varones ${ }^{5}$. Las causas de esta amplia mortalidad masculina, con un mayor número de defunciones entre los 20 y 50 años, en Germania Superior, y entre los 30 y 50 años en Germania Inferior, se debe principalmente a las actividades bélicas que tuvieron un carácter preferente en la zona fronteriza del Rhin. En este sentido hay que indicar que la mayor parte de los fallecidos son soldados ${ }^{6}$, que prestaron sus servicios militares en Germania Superior o en Germania Inferior donde murieron. En aquellos casos en que conocemos el status del difunto se aprecia que la mortalidad de los individuos sometidos a un régimen de dependencia personal en ambas provincias germanas tuvo lugar a una edad temprana, siendo mayor el número de defunciones entre los 10 y los 20 años en Germania Superior, como Peregrinus ${ }^{7}$, siervo que murió a los diez años; Romanus ${ }^{8}$, siervo que falleció a los doce años; Diadumenus ${ }^{9}$, verna que vivió hasta los dieciseis años, al igual que Coteia Prima ${ }^{10}$, que era liberta; Priscus ${ }^{11}$, siervo que falleció a los diecisiete años; Antiphilus ${ }^{12}$, liberto que murió a los dieciocho años, lo mismo que Modestus ${ }^{13}$, que era siervo; y Rhodine ${ }^{14}$, esclava que fallece a los veinte años. Además, dos niños mueren a la edad de un año, $L y c n i{ }^{15}$, que era

\footnotetext{
4 Vid. Tablas de mortalidad en Germania Superior y Germania Inferior.

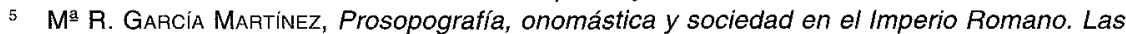
estructuras sociales. Las provincias de Germania Superior y Germania Inferior, Universidad de Valladolid, 1996 (microficha); Idem, Germania Romana. Las estructuras sociales, Universidad de Valladolid (en prensa).

6 Vid. Tablas de datos de la mortalidad en Germania Superior y Germania Inferior apartado de profesión.

7 CIL XIII, 6109.

8 CIL XIII, 7106.

9 N-BRGK, 1937, 110.

10 CIL XIII, 5312.

CIL. XIII, 6888.

CIL XIII, 5016.

AE, 1977, 590.

CIL XIII, 11889.

15 CIL XIII, 7089.
} 
ancilla y Coteia Araurica ${ }^{16}$, que era liberta. En Germania Inferior, el número de fallecimientos de los esclavos y libertos es más elevado entre los 10 y los 25 años, como lulia Primigenia ${ }^{17}$, que era liberta, muere a los tres años; Ascanius ${ }^{18}$, siervo que murió a los doce años; Romanius Modestus ${ }^{19}$, liberto que falleció a los dieciseis años, Ti. Claudius Halotus $^{20}$, liberto que muere a los dieciocho años, Anthus ${ }^{21}$, siervo que fallece a los veinte años, Prospectus ${ }^{22}$, que vivió veintidós años y un siervo Anonymus ${ }^{23} 6$, que muere a los diecisiete años.

Los documentación sobre la mortalidad infantil pone de manifiesto que hubo un mayor porcentaje de defunciones a la edad de un año ${ }^{24}$, dos años ${ }^{25}$, y entre los cinco y diez años ${ }^{26}$.

En función de los datos demográficos referentes a la mortalidad verificamos que la esperanza media de vida no era demasiado elevada, por ello resulta digno de mencionar la longevidad de un grupo de individuos que fallecieron entre los 80 y los 100 años en Germania Superior, Atuns ${ }^{27}$, Petus ${ }^{28}$, Saturninus ${ }^{29}$ y Vinda ${ }^{30}$, que murieron a los ochenta

16 CIL XIII, 5312.

CIL XIII, 8593.

CIL XIII, 8108 .

CIL XIII, 8115.

CIL XIII, 8271.

CIL XIII, 8108.

CIL XIII, 8108.

SCH-BRBG, 1977, 177.

24 En Germania Superior, L. Aelius Urbicus (CIL XIII, 5244); Coteia Araurica (CIL XIII, 5312); Visellia Firma (AE 1990, 769); Lycnis (CIL XIII, 7089); En Germania Inferior, Leontius (N-BRGK $1937,227)$ y Ursa (CIL XIII, 8406).

25 En Germania Superior, Aelia Modestina (CIL XIII, 11834); Antullus (CIL XIII, 11874); Bononia (CIL XIII, 7062A); Samocna (CIL XIII, 11888). En Germania Inferior, Catulus (AE 1981, 673); Primigenia (ClL XIII, 8556).

26 En Germania Superior, a los cinco años mueren: L. Canuleius Sucessus (CIL XIII, 7082$) ; L$. Licinius Sacerdos (CIL XIII, 11942): liiomarus (CIL XIII, 5392); Anonymus 6 (CIL XIII, 6155) y Anonymus 13 (ClL XIII, 11907); Mirio (CIL XIII, 11732A) a los 4 años; lanuarius (CIL XIII, 11881) y Anonyma 1 (CIL XIII, 7096) a los 7 años; Primio (AE 1979, 431) y Respectus (CIL XIII, 11888) a los 8 años; lanussius lanuaris lunior (CIL XIII, 5391) a los 9 años; y a los diez años: Flavius? Natalis (CIL XIII, 5769); Vitalinius Gromatius (CIL XIII, 7122), Pardulus (CIL XIII, 5177) y Peregrinus 10 (CIL XIII, 6109). En Germania Inferior, C. lulius Eutichestatus Touscus (AE 1984, 660) e innocentia (CIL XIII, 8324) mueren a los 7; Severinus (CIL XIII, 8431) a los 8 años y Lupassius (CIL XIII, 8404) a los 9 años. Vid. Tablas de datos.

27 CIL XIII, 6460.

28 CIL XIII, 6393.

29 CIL XIII, 5332.

so CIL XIII, 7101. 
años; Leubius ${ }^{31}$, que vivió 81 años; Blussus ${ }^{32}$, fallece a los 85 años; $L$. Camillius Faustus ${ }^{33}$, a los 92; Nicasius ${ }^{34}$, que era siervo, murió a los 100 años al igual que, Pusa ${ }^{35}$, Dometius lumma ${ }^{36}$ y Flavius Sterius ${ }^{37}$, que también fallecieron a la edad de cien años. En Germania Inferior, no hemos encontrado muestras epigráficas de individuos que vivieran más de 65 años.

La causa que ocasionó la muerte se especifica en un reducido número de epitafios en las dos provincias germanas ${ }^{38}$. Así, Clodius Perigenes ${ }^{39}$, interfecere latrones, al igual que Rogatinius? Romulus ${ }^{40}$, interceptus; Flavius Marinianus ${ }^{41}$, Liberalinius Vitalis ${ }^{42}, M$. Caelius ${ }^{43}$, Biribam ${ }^{44}$, Viatorinus ${ }^{45}$ murieron en la guerra ${ }^{46}$; lulia Prisca ${ }^{47}$, falleció por un error del médico; $M$. Terentius lucundus ${ }^{48}$, liberto que se suicidó después de haber asesinado a sus siervos; Paulla ${ }^{49}$, que muere por una enfermedad,
CIL XIII, 11709.
CIL XIII, 7067.
CIL XIII, 5097.
CIL XIII, 11833.
CIL XIII, 7101.
CIL XIII, 6460.
CIL XIII, 6328.
38 H. Gallego Franco, M" R. Garcia Martínez \& F. J. Garcia de Castro, "Mortes singulares: Testimonios epigráficos en el Occidente romano», Homenaje Montenegro, Universidad de Valladolid, 1997 (en prensa).

${ }^{39}$ CIL XIII, 6429. Su hermano $P$. Clodius Perigenes le dedica el epitafio, que se fecha en los siglos II-III.

${ }^{40}$ CIL XIII, 5192. Está dedicado por sus padres, Sat... Aventina y Sat... Senatus. Murió a los 25 años. Se fecha en los siglos II-1II.

41 CIL XIII, 6317. Era miles de la Legio VIII Augusta y murió en una expedición, functus expeditione Germanica.

42 CIL XIII, 8070. Era eques de la Legio / Minerva y murió bello desideratus.

${ }_{43}$ CIL XIII, 8648. Centurio de la Legio XIIX, natural de Bononia. Murió a los 53 años cecedit bello Varriano.

44 CIL XIII, 7323. Decurio alae firmae, originario de la provincia de Mesopotamia. Murió Bello desideratus.

45 ClL XIII, 8274. Este soldado muere a los 30 años, occisus in barbarico iuxta Divitia a Franco.

${ }^{46}$ Las fórmulas que se emplean son functus expeditione, bello desideratus, occisus in barbarico y cecedit bello.

47 AE 1952, 16 = NL BRGK 1959, 105. Esta inscripción se fecha en época de Augusto. Esta mujer muere a la edad de 20 años por medici deflerem ego culpam.

48 CIL XIII, 7070. Este individuo era pecuarius. Su patrono le dedica el epitafio. Murió a los 30 años, ipse praecipitem sesse deiecit in amnem.

49 AE 1938, 120 = N BRGK 1937, 113. Paulla murió a los 28 años por una causa dolorosa, pero desconocemos qué tipo de enfermedad pudo provocar su fallecimiento. 
al igual que Honoratianus ${ }^{50}$, que fallece precipitadamente sin que aún pudiera hablar. En otros casos se alude a la circunstancia en que se produjo la muerte, así Hipponicus ${ }^{51}$, expletis ter centum ter denisque diebus invisae Parcae solemnem celebrare diem; Aelianus ${ }^{52}$, que muere lejos de su patria, al igual que un individuo Anonymus ${ }^{53}$.

Los movimientos migratorios en las provincias germanas constituyen el otro aspecto demográfico analizado también a través de los testimonios epigráficos. La mención de la origo en los epitafios nos sirve para comprobar desde que zonas del Imperio romano se producen movimientos migratorios hacia Germania Superior y Germania Inferior, constatándose los motivos que provocaron el desplazamiento, así como el grupo gentilicio al que pertenecen los individuos que se trasladan a dichas provincias. Las familias con un mayor número de miembros procedentes de otras provincias son los Valerii y los lulii en Germania Superior, y los Iulii y los Aurelii en Germania Inferior. Los factores que incidieron en estos desplazamientos fueron primordialmente de índole militar ${ }^{54}$, y por ello la inmensa mayoría de los individuos originarios de otras zonas del Imperio eran soldados ${ }^{55}$, circunstancia que se encuentra en directa relación con el hecho de que era necesario mantener en las provincias germanas un contingente militar permenente que se ocupara de la defensa del limes rhenano. Entre los centros de origen de los indivividuos que se desplazan hacia las provincias germanas, Italia aporta un volumen de soldados bastante considerable a la provincia de Germania Superior y a Germania Inferior, aunque en esta última en menor proporción. Se enviaron efectivos militares desde diversas ciudades de la provincia de Italia ${ }^{56}$, pero sobre

50 NL BRGK 1959, 142. Honoratianus, muere de meses fatis properantibus infans, bis quinis tantum qui vixit mensibus.

$51 \mathrm{CIL}$ XIII, 6808. Hipponicus era siervo de Dignilla, esposa del legado lunius Pastor (PIR2 522). Sus padres, Hydyepes y Genesia, realizan la dedicatoria. Se fecha en el año 163.

52 CIL XIII, 8699. Este individuo era praefectus de la Cohors II. Era natural de Mauritania, circunstancia que menciona en su epitafio, terra peregrina obruit.

53 CIL XIII, 6496. El epígrafe se encuentra fragmentado y desconocemos el nombre de este individuo, que era negotiator paenularius, natural de Cappadocia. Muere a los 35 años praematura procul a patria.

54 R. CheValier, Voyages et deplacements dans l'Empire Romain, París, 1988; M.R. García Martínez, "Caracteres y significación socio-económica de los movimientos de población hispana hacia las provincias imperiales en época romana», HAnt, XV, 1991, 263-301.

55 Vid. Tabla de datos de los Movimientos migratorios.

56 Cfr. Tabla de datos: Movimientos migratorios, apartado Urbsindivi. 
todo desde Mediolanum ${ }^{57}$ y Placentia ${ }^{58}$. En relación con este predominio de los militares que proceden de la zona italiana, cabe destacar que al examinar los distintos grupos de cognomina hemos verificado que precisamente en la categoría de antropónimos étnico-geográficos manifiestan un predomino los onomásticos relativos a distintos lugares de Italia como Sabinus ${ }^{59}$, Florentinus ${ }^{60}$, Romanus ${ }^{61}$, Albanus ${ }^{62}$, Lucanus ${ }^{63}$, Aventinus ${ }^{64}$, aspecto que podría deberse quizá a esa abundancia de soldados originarios de la provincia de Italia, que recuerdan la patria a través del cognomen. También otras provincias contribuyeron al mantenimiento militar de la zona fronteriza del Rhin, como Gallia Narbonensis, Gallia Lugdunensis, Gallia Belgica, Hispania ${ }^{65}$, Africa, Dalmatia, Pannonia, Noricum y Virunum ${ }^{66}$. Los focos de recepción de estos desplazamientos se localizan de un modo prioritario en las ciudades y campamentos establecidos a lo largo de la orilla izquierda del Rhin, debido precisamente a ese carácter militar de dichos desplazamientos. Los centros que reciben un mayor número de individuos son en Germania Superior, Mogontiacum, Kastel, Zalbach, Wiesbaden, Argentorate, Baden-Baden y Vindonissa; y en Germania Inferior Colonia Ara Agrippinensium, Bonna, Noviomagus, Castra Vetera y Ricomagus. Estos traslados de militares a la zona de Germania romana tuvieron lugar a lo largo de todo el Imperio, pero con una mayor abundancia entre los siglos I y III.

57 En Germania Superior: Ti. Babuleius Garrulus (CIL XIII, 5976); C. Cassius y M. Cassius (AE 1977, 586); C. Cassius Geminus (CIL XIII, 11853); T. Flavius Peregrinus (CIL XIII, 5979); M. Novellius Romanus (CIL XIII, 6967); C. Valerius Virillio (SCH-BRGK 1977, 67), Q. Valerius Virillio (CIL XIII, 6975), L. Varius Sacco (CIL XIII, 11855); C. Pompeius (CIL. XIII, 11858). En Germania Inferior, C. Calventius (CIL XIII, 8644) y Q. Petilius Secundus (CIL XIII, 8079).

58 En Germania Superior: Aebutius Primus (CIL XIII, 6885); L. Antistius (CIL XIII, 6936); G. Ennius Titus (N-BRGK 1937, 61); M. Iguinus Valens (AE 1979, 434); C. Octavius Octavius (SCH-BRGK 1977, 73); C. Veturius Dexter (CIL XIII, 11717); L. Veturius Primus (CIL XIII, 7575);

Q. Vibius Rufus (AE 1979, 434); T. Viccius (CIL XIII, 6946); Fronto? (AE 1979, 435).

59 Kajanto, 20, 30bis, 51, 186.

60 Kajanto, 28, 45, 46, 189, 233.

61 Kajanto, 20, 30, 51, 182.

62 Kajanto, 44, 181.

63 Kajanto, 193.

64 Kajanto, 183.

65 J.M. ROLdÁN, Hispania y el ejército romano, Salamanca, 1974; A. Alonso Avila \& S. Crespo Ortiz de Zárate, "Contactos y relaciones entre las provincias de Germania e Hispania durante el Alto Imperio romano", HAnt, XVI, 1992, 171-187.

66 Vid. Tabla de datos: Movimientos migratorios en Germania Superior y Germania Inferior. 
Además de los motivos militares, hemos corroborado que en los movimientos migratorios hacia las provincias germanas también intervinieron los factores de carácter comercial ${ }^{67}$, que determinaron el traslado a Germania Superior de algunos individuos dedicados al comercio, así Fufidius ${ }^{68}$, negotarior cretarius originario de Britannia, que se trasladó a Mogontiacum y un individuo cuyo nombre desconocemos, Anonymus ${ }^{69}$, que era negotiator paenularius y se desplaza a Waldmuhlbach, ya mencionado. En Germania Inferior, C. Aurelius Verus ${ }^{70}$, negotiator originario de Britannia, al igual que $M$. Secundinius Silvanus ${ }^{71}$ y $M$. Secundius Silvanus ${ }^{72}$, que eran negotiatores cretarii y ambos procedían de Britannia; C. Catullinius Secco ${ }^{73}$, negotiator allecarius, originario de Trever y $P$. Arisenius ${ }^{74}$, negotiator Britannicianus.

Aunque también tenemos constatación de movimientos migratorios internos en las provincias germanas, sin embargo presentan una proporción muy reducida si se comparan con los desplazamientos desde otras zonas del Imperio citados anteriormente ${ }^{75}$.

En conclusión, los datos sobre la mortalidad en las provincias de Germania Superior y Germania Inferior extraídos de las fuentes epigráficas evidencian que se produjeron un mayor número de muertes entre los 20 y los 50 años en Germania Superior y entre los 30 y los 50 años en Germania Inferior ocasionadas principalmente por la actividad militar. El porcentaje de varones fallecidos resulta bastante superior al número de mujeres que han dejado constancia de su edad, que es exiguo. Son sobre todo soldados, que contribuyeron a la defensa del limes rhenano, los que mencionan en sus epitafios la edad. Se comprueba que los individuos sometidos a un régimen de dependencia personal suelen fallecer a una edad

67 R. CheVAlier, Voyages et deplacements dans I'Empire Romain, París, 1988; Alonso ÁvILA \& S. CRESPO ORTIZ DE ZARATE, "Contactos y relaciones entre las provincias de Germania e Hispania durante el Alto Imperio romano», HAnt, XVI, 1992, 171-187.M.R. GARCiA MARTinEZ, "Caracteres y significación socio-económica de los movimientos de población hispana hacia las provincias imperiales en época romana", HAnt, XV, 1991, 263-301.

68 CIL XIII, 7300.

69 CIL XIII, 6496.

70 CIL XIII, 8164A.

$71 \quad \mathrm{AE}, 1973,370$.

72 CIL XIII, 8793.

73 AE, 1973, 375.

74 AE, 1983, 720.

75 Vid. Tablas de datos de los movimientos migratorios en ambas provincias germanas. 
temprana. Por otro lado, entre los motivos que influyeron en los movimientos migratorios hacia las provincias germanas, el factor militar ocupa un lugar prioritario, debido a esa necesidad de disponer de un contingente militar permanente en la zona fronteriza del limes. En segundo lugar, el factor económico también incidió directamente en el desplazamiento de individuos dedicados a la actividad comercial, que abastecieron a las provincias germanas de algunos productos. Se desplazaron hacia Germania individuos que pertenecían a diferentes grupos gentilicios, con una prioridad de los Valerii y los Iulii en Germania Superior, y los Iulii y los Aurelii en Germania Inferior. La provincia que aportó un mayor número de soldados en ambas Germanias, fue Italia, sobre todo Mediolanum y Placentia, pero también proporcionaron efectivos militares Gallia Narbonensis, Gallia Lugdunensis, Gallia Belgica, Hispania, Africa, Dalmatia, Pannonia, Noricum y Virunum. 


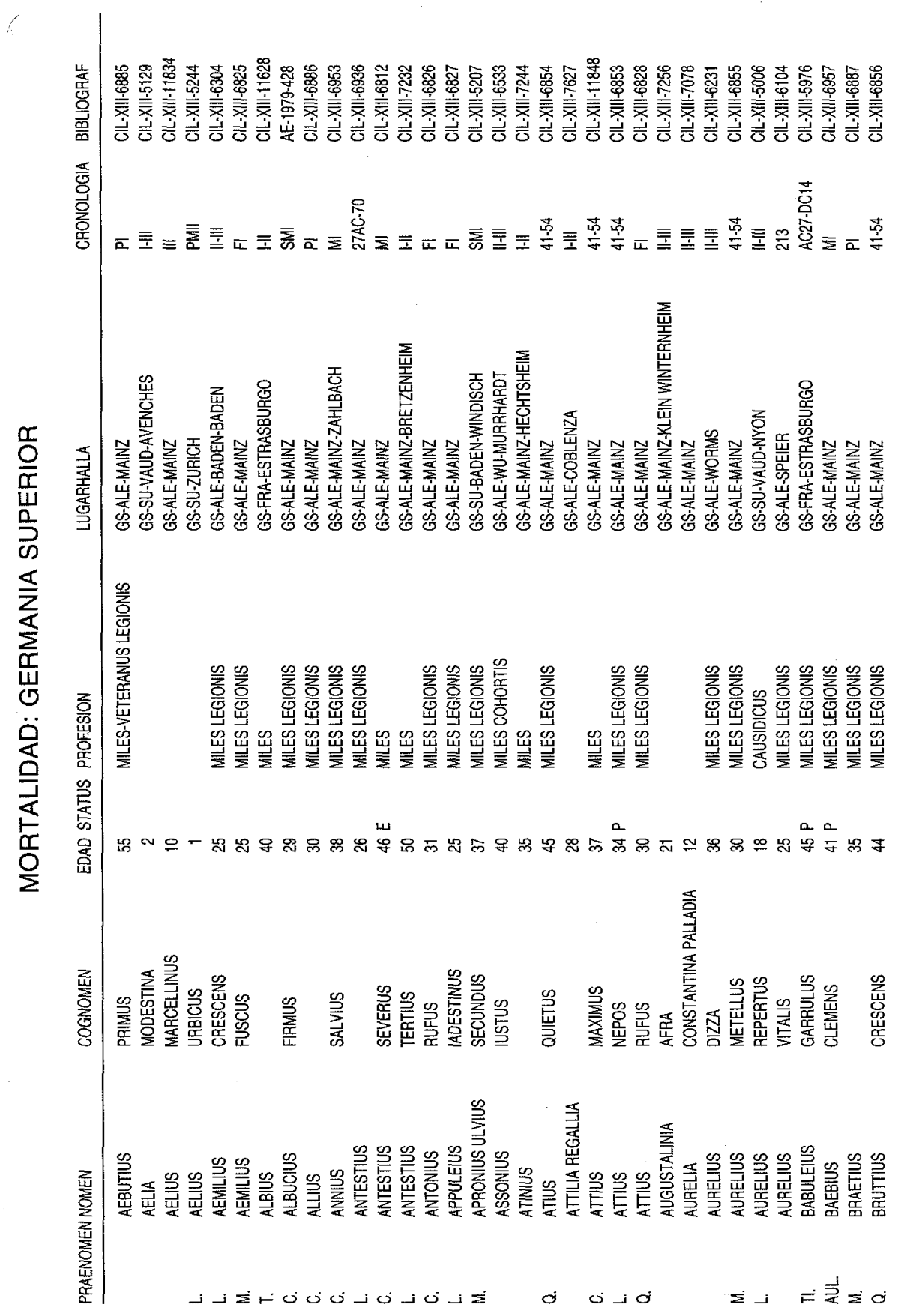




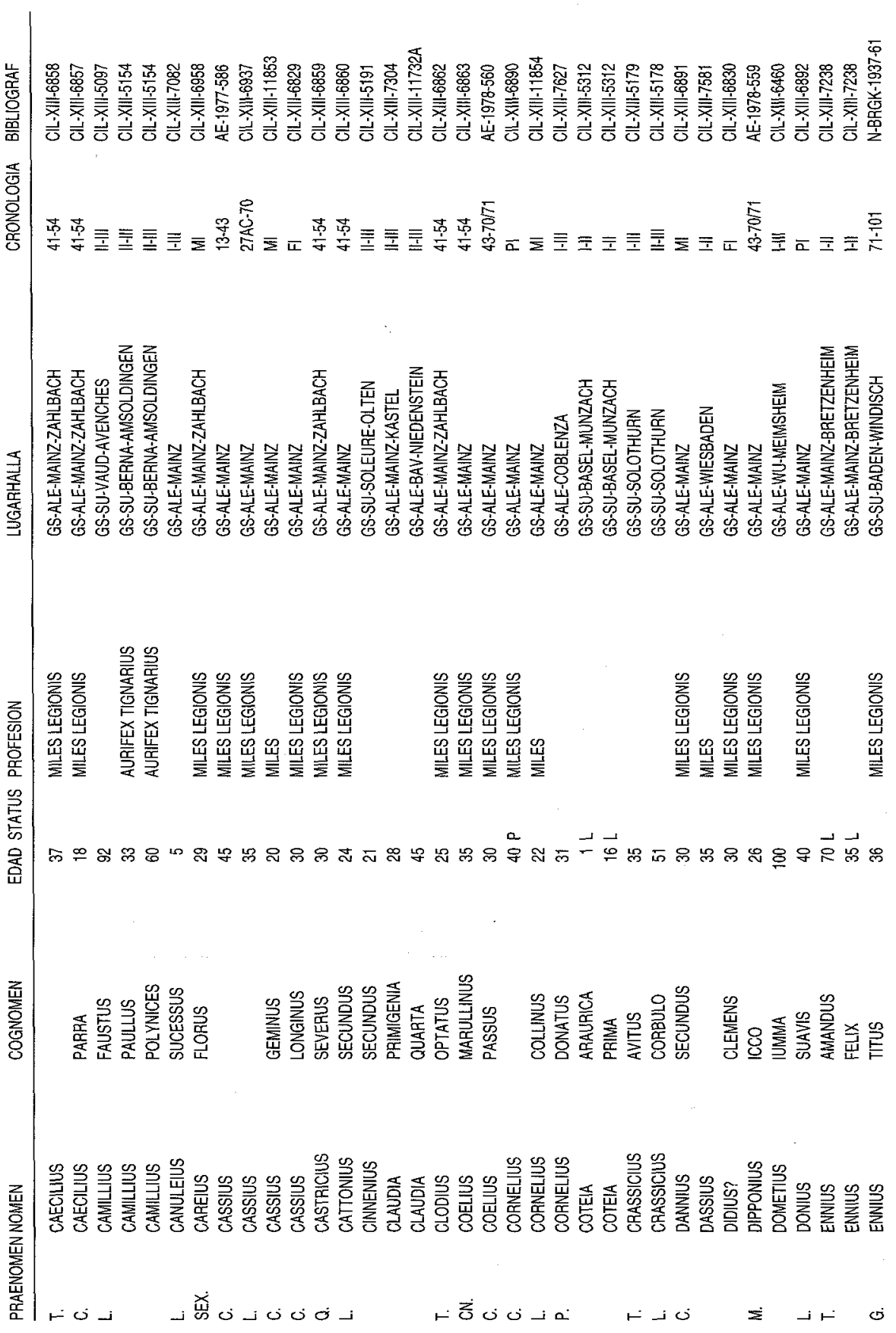




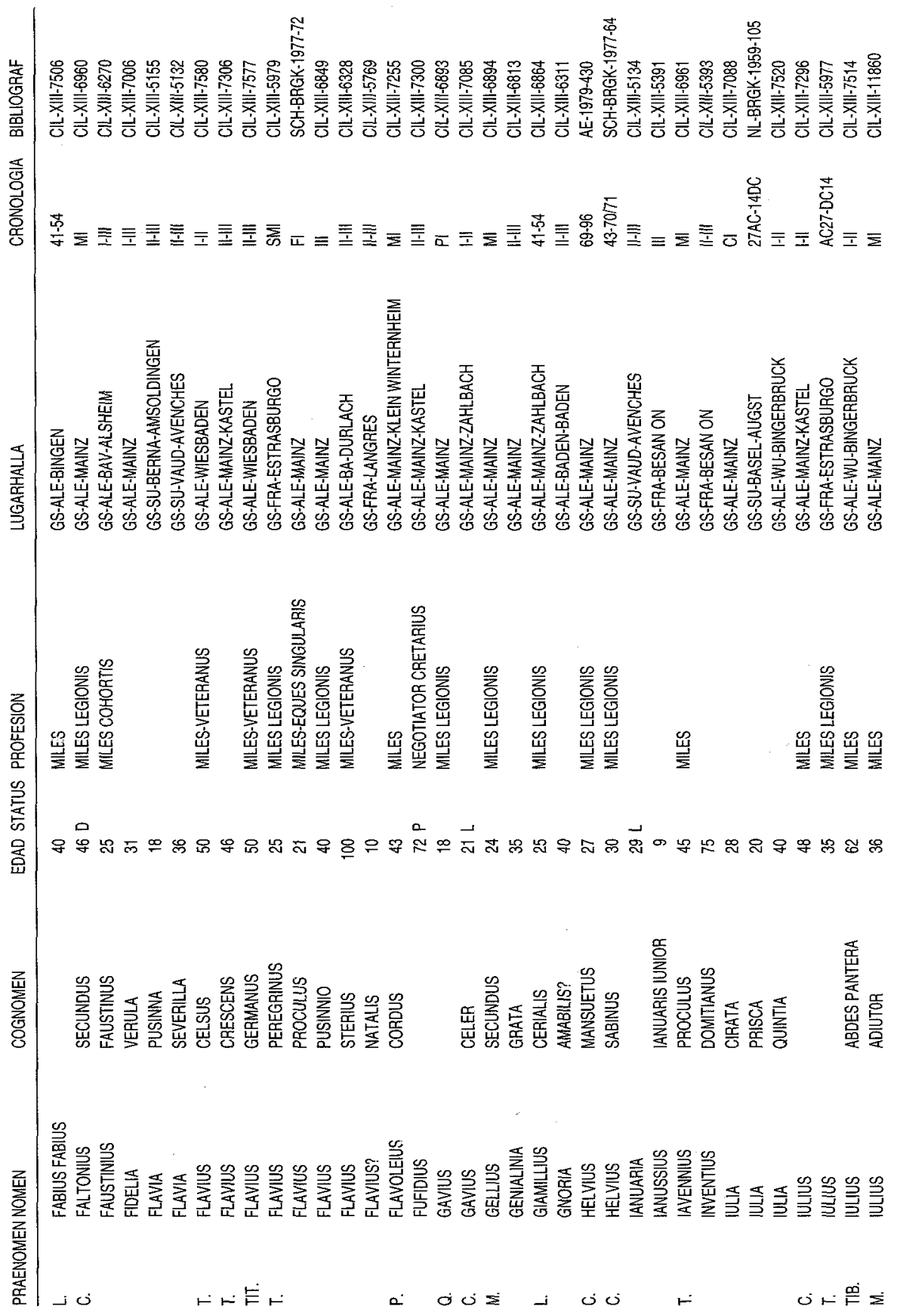




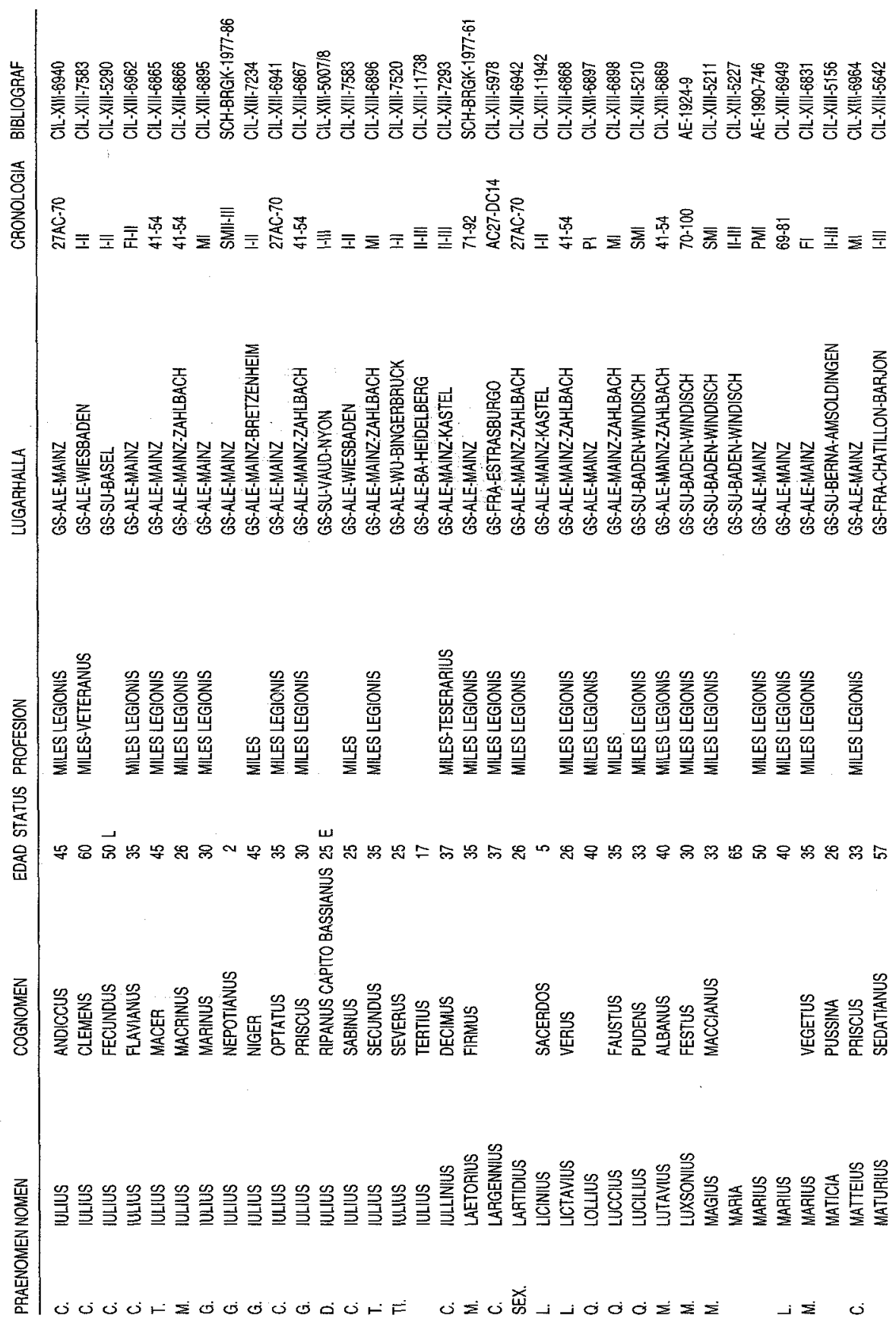




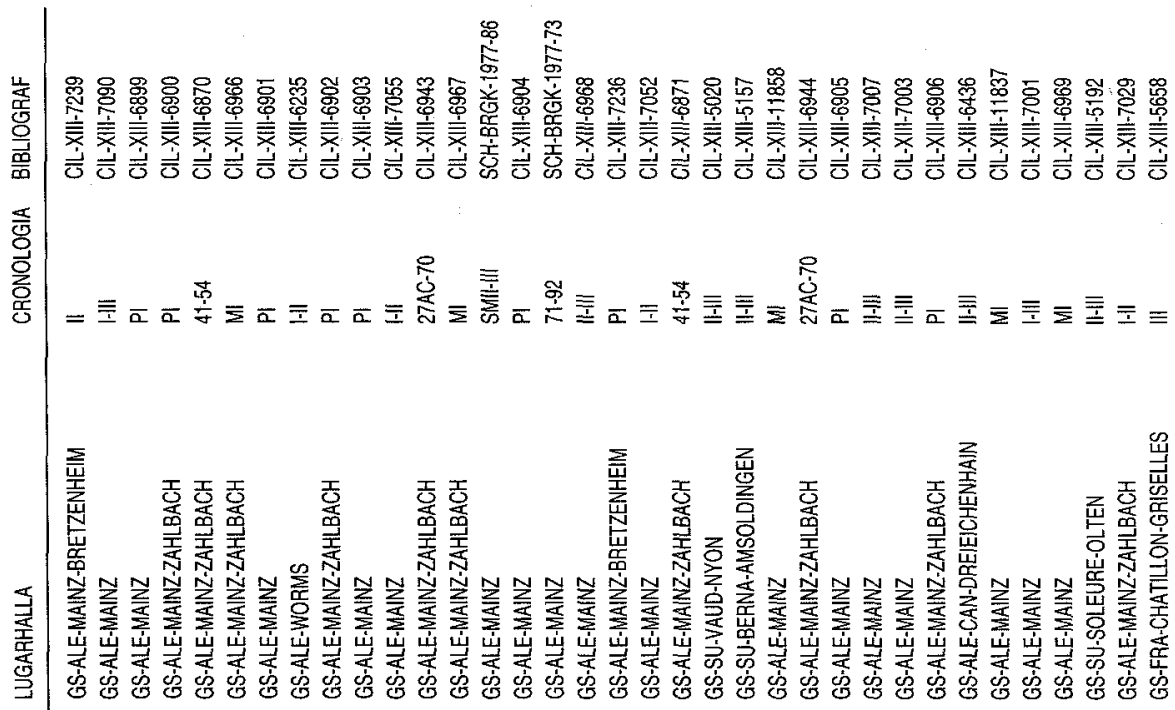

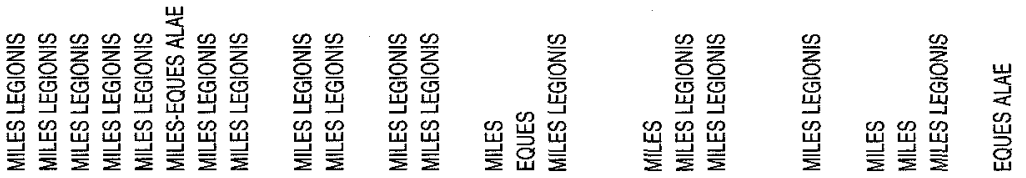

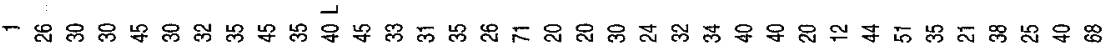

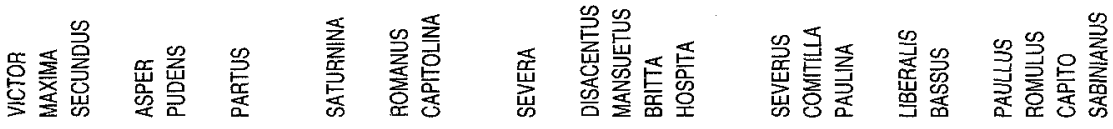<smiles>[Ca][Hg]</smiles>

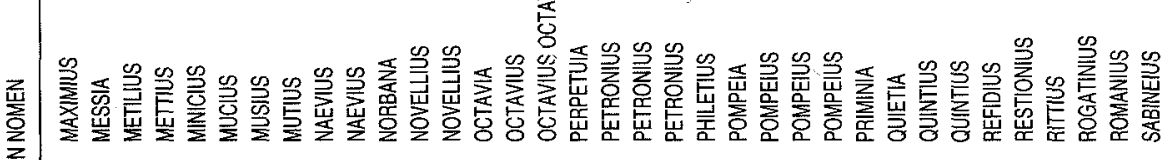

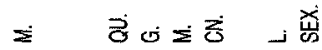




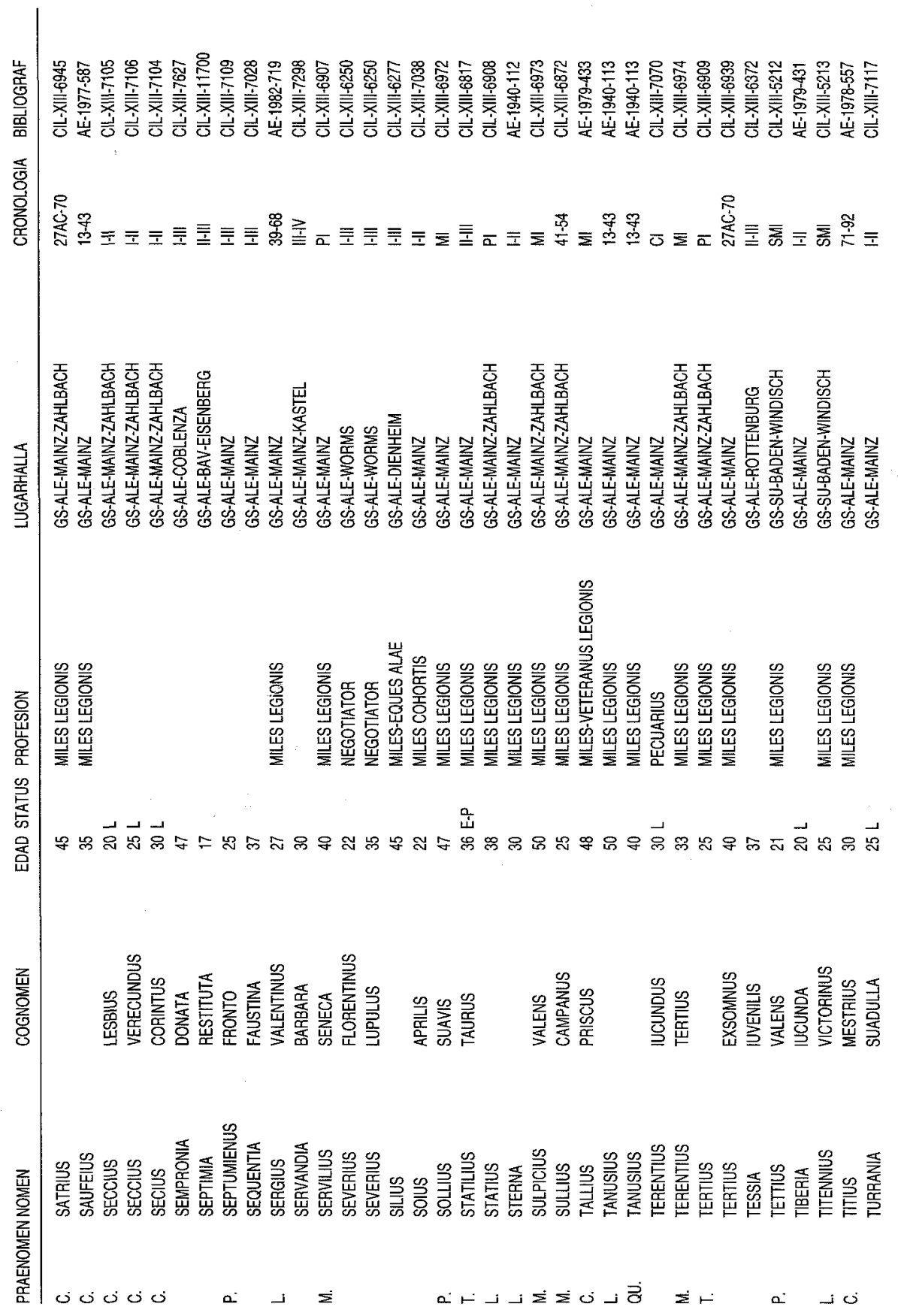




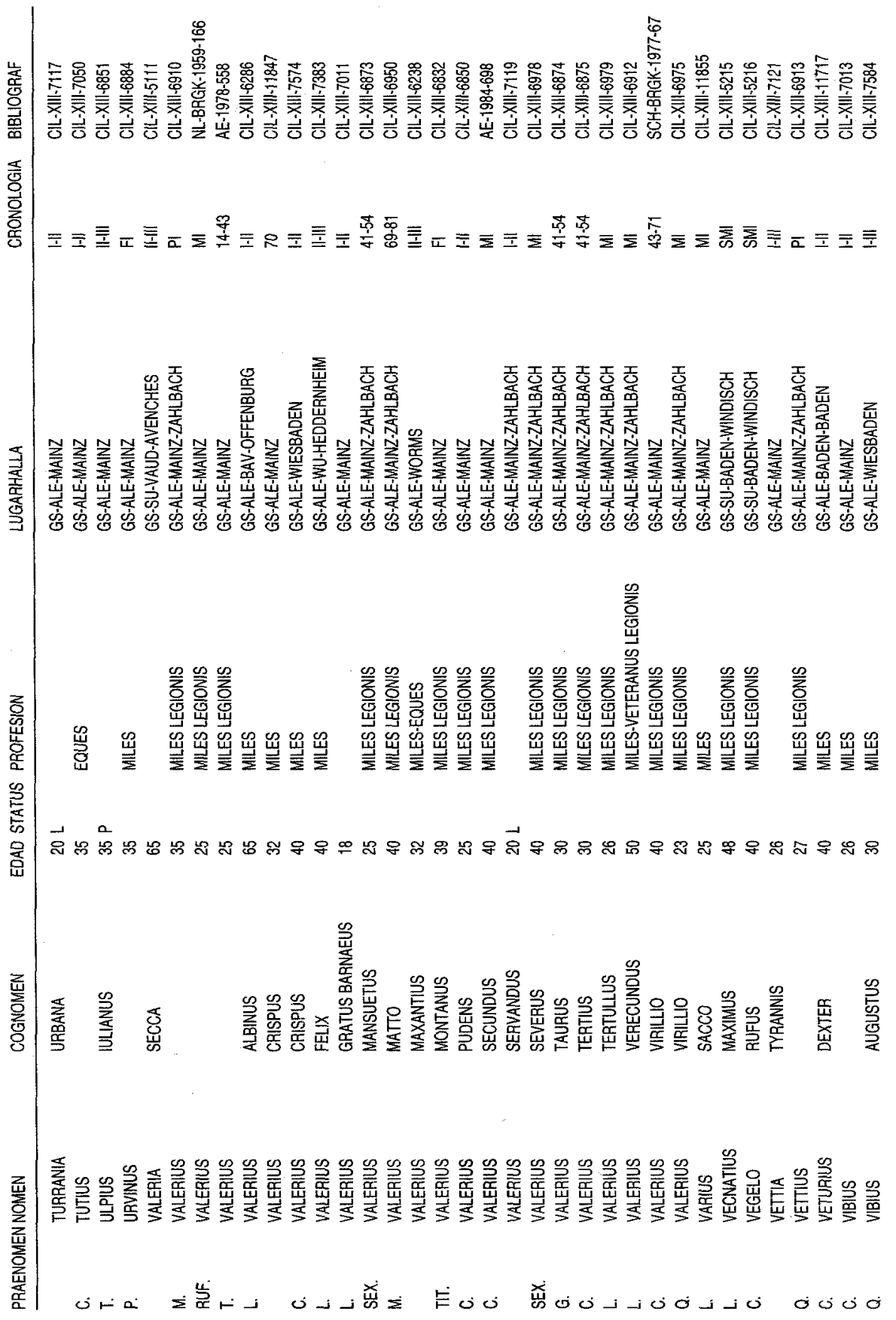




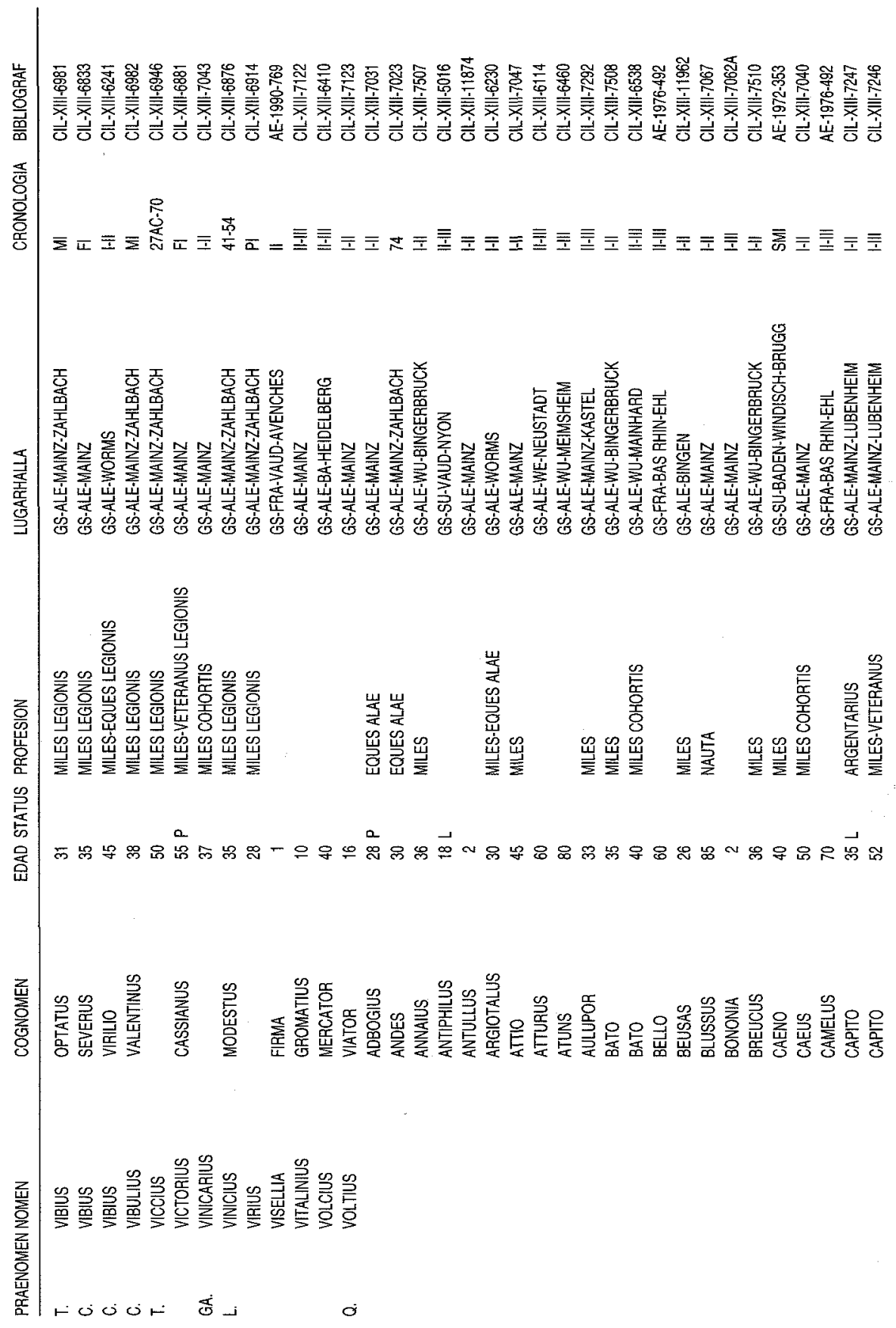




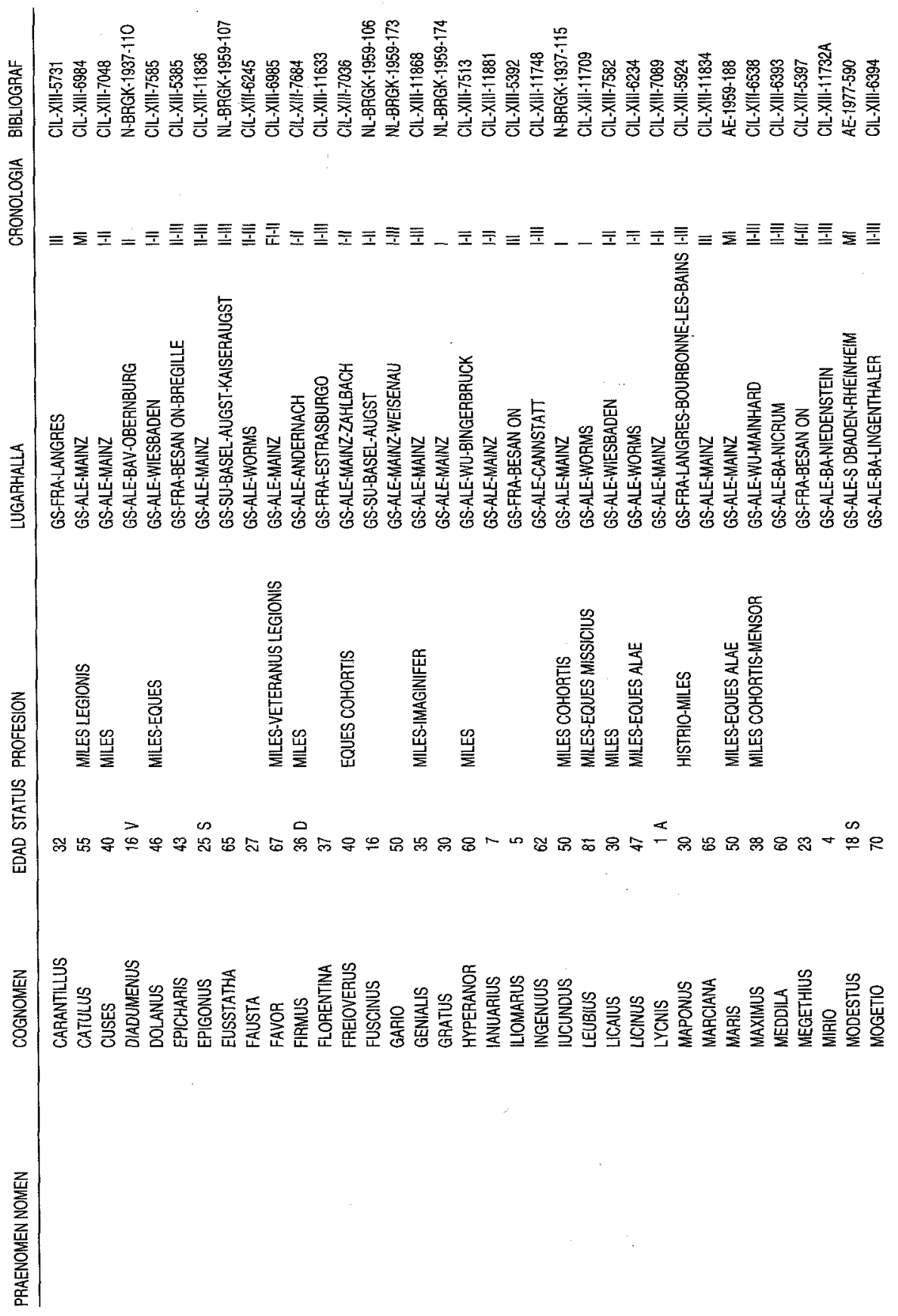




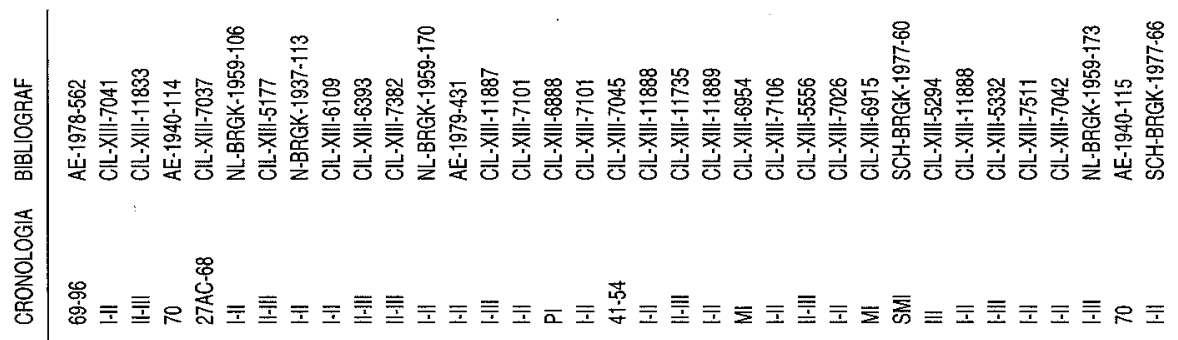

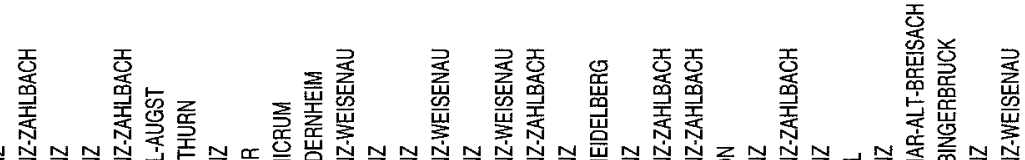

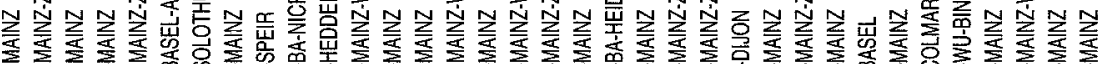

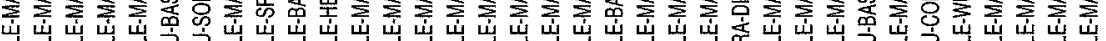

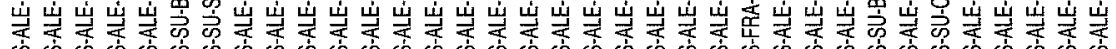

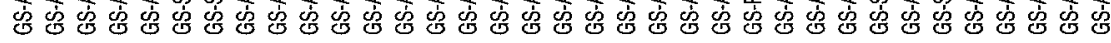

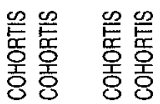

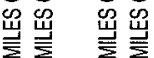

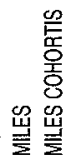



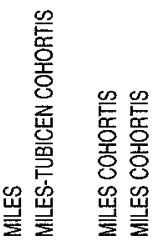

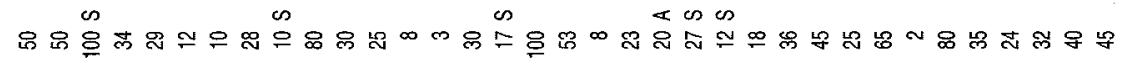




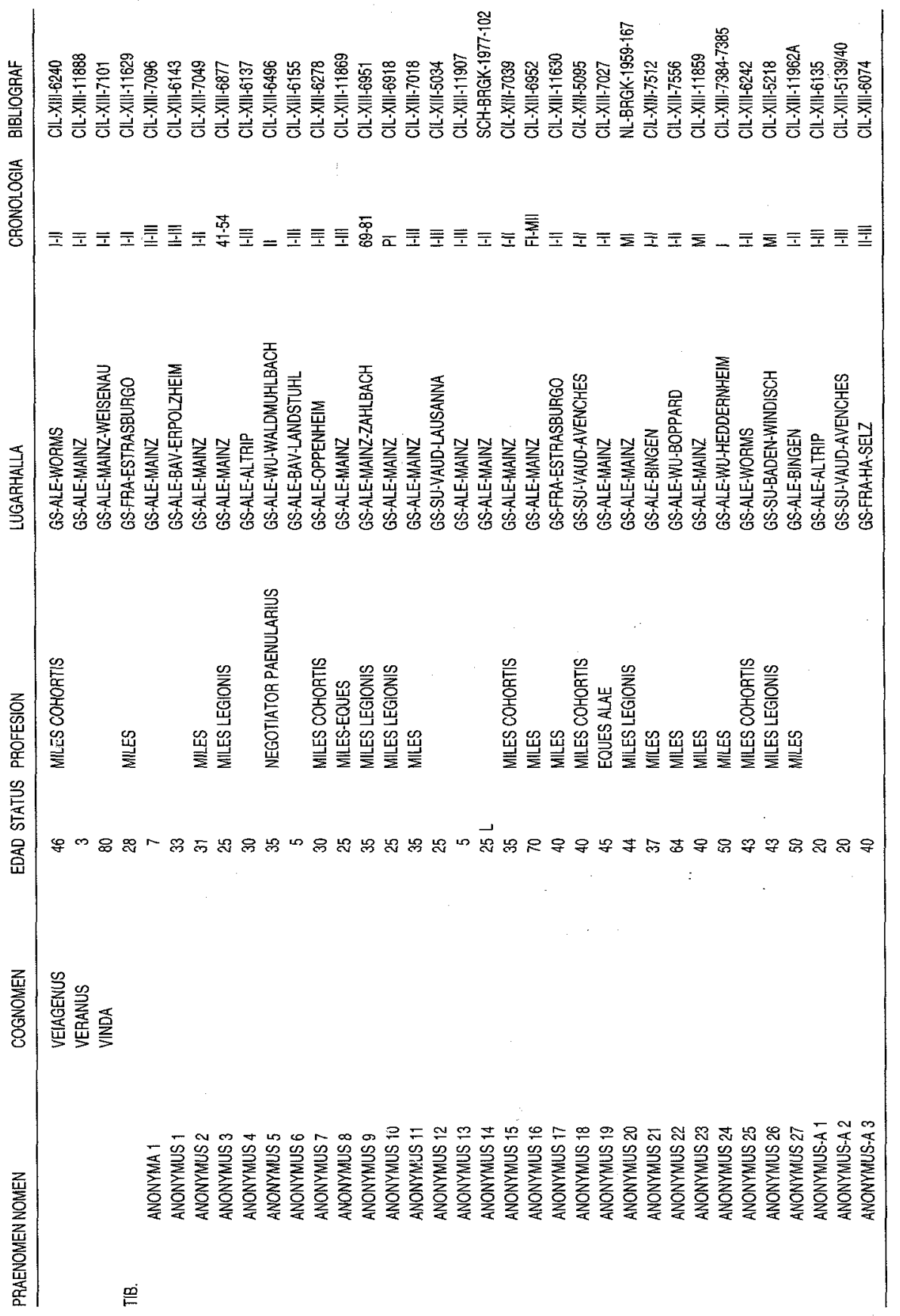




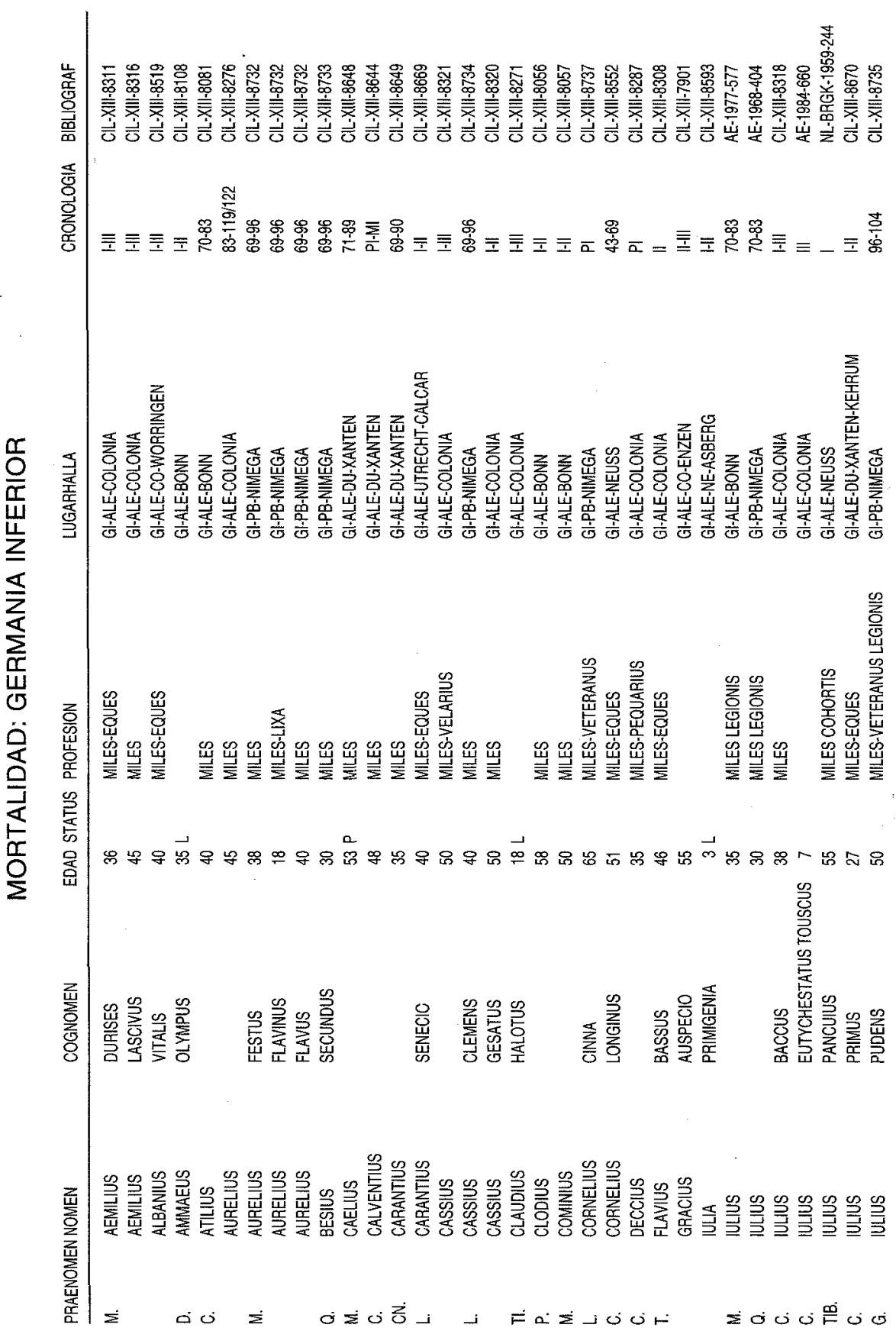




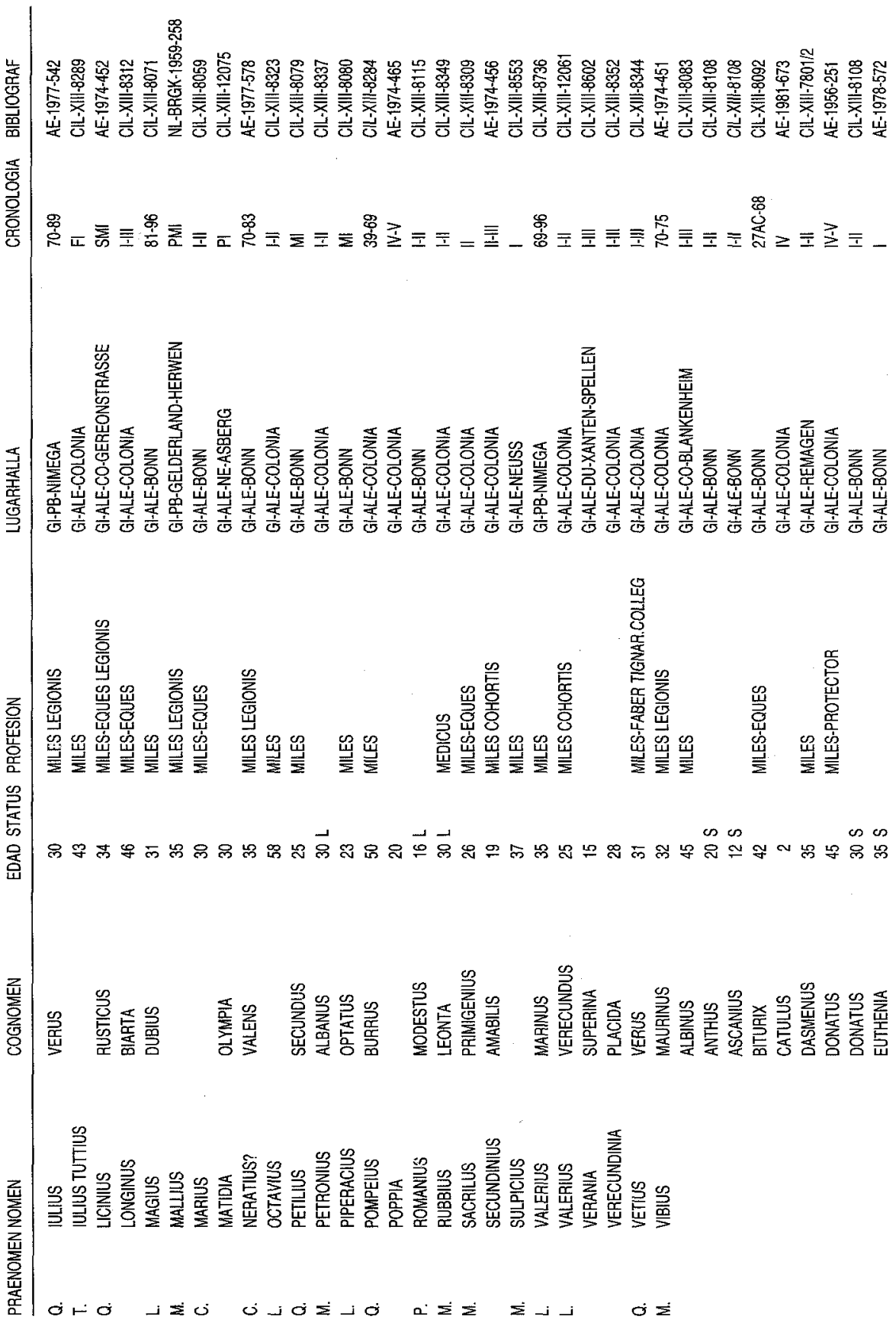




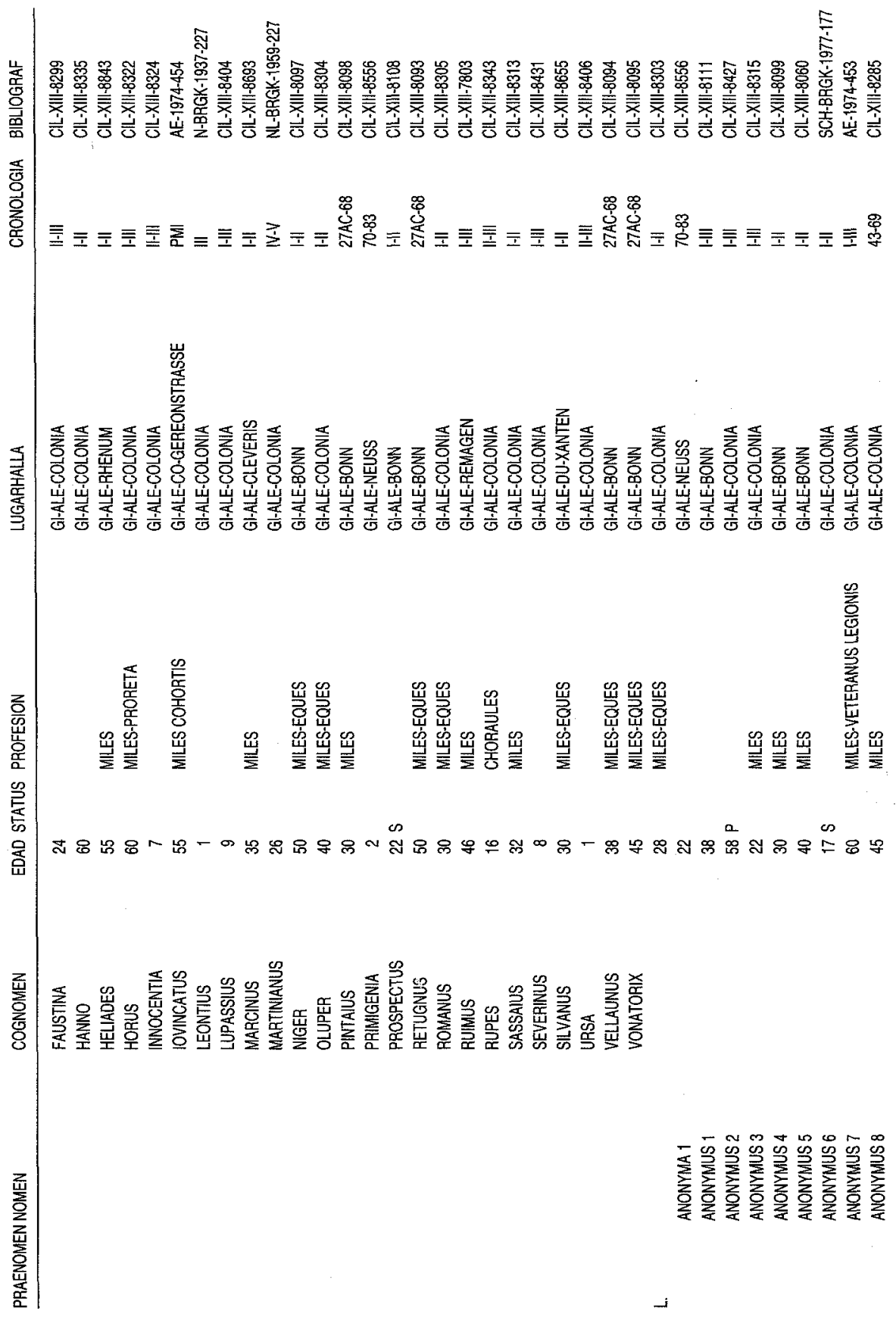




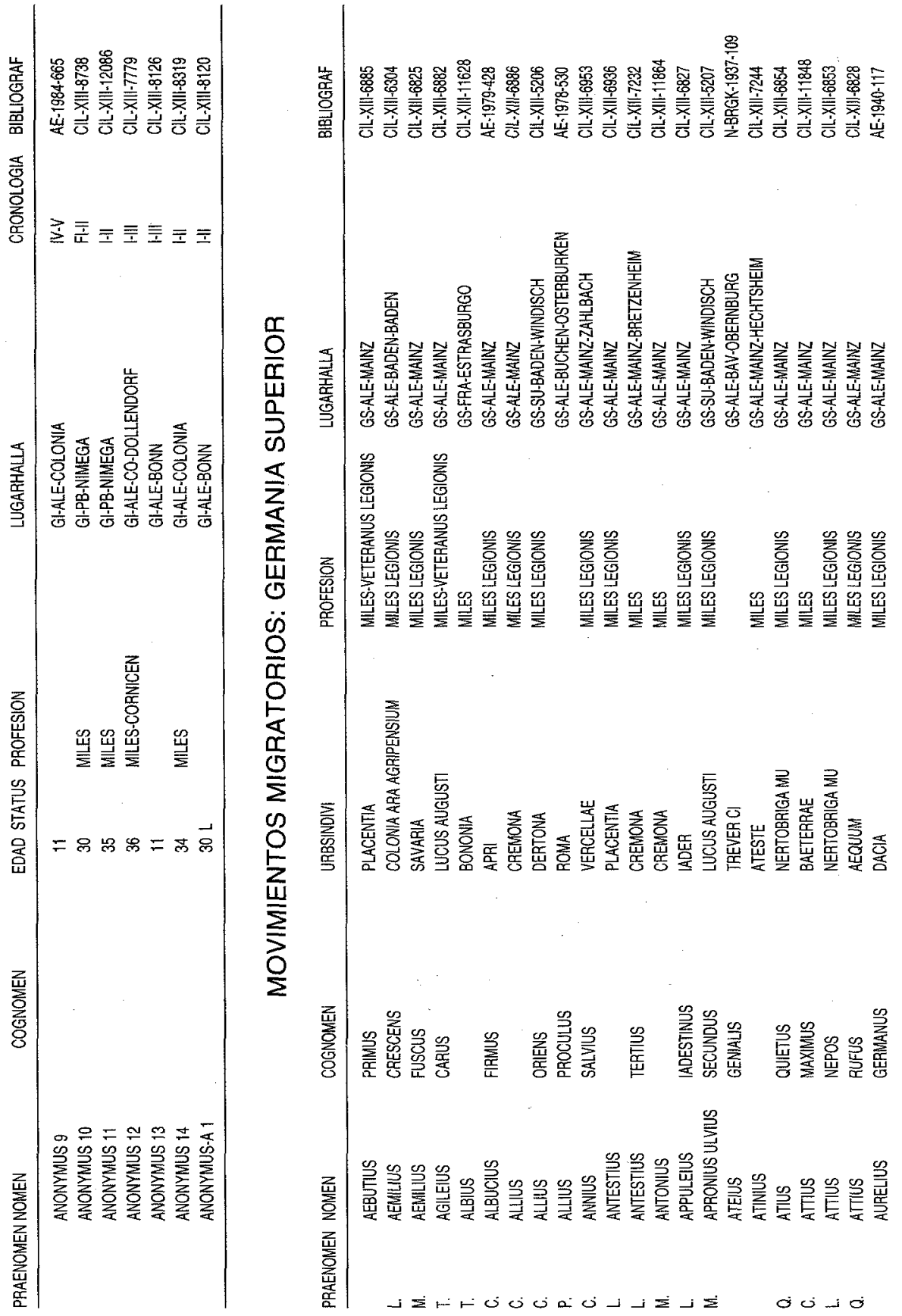




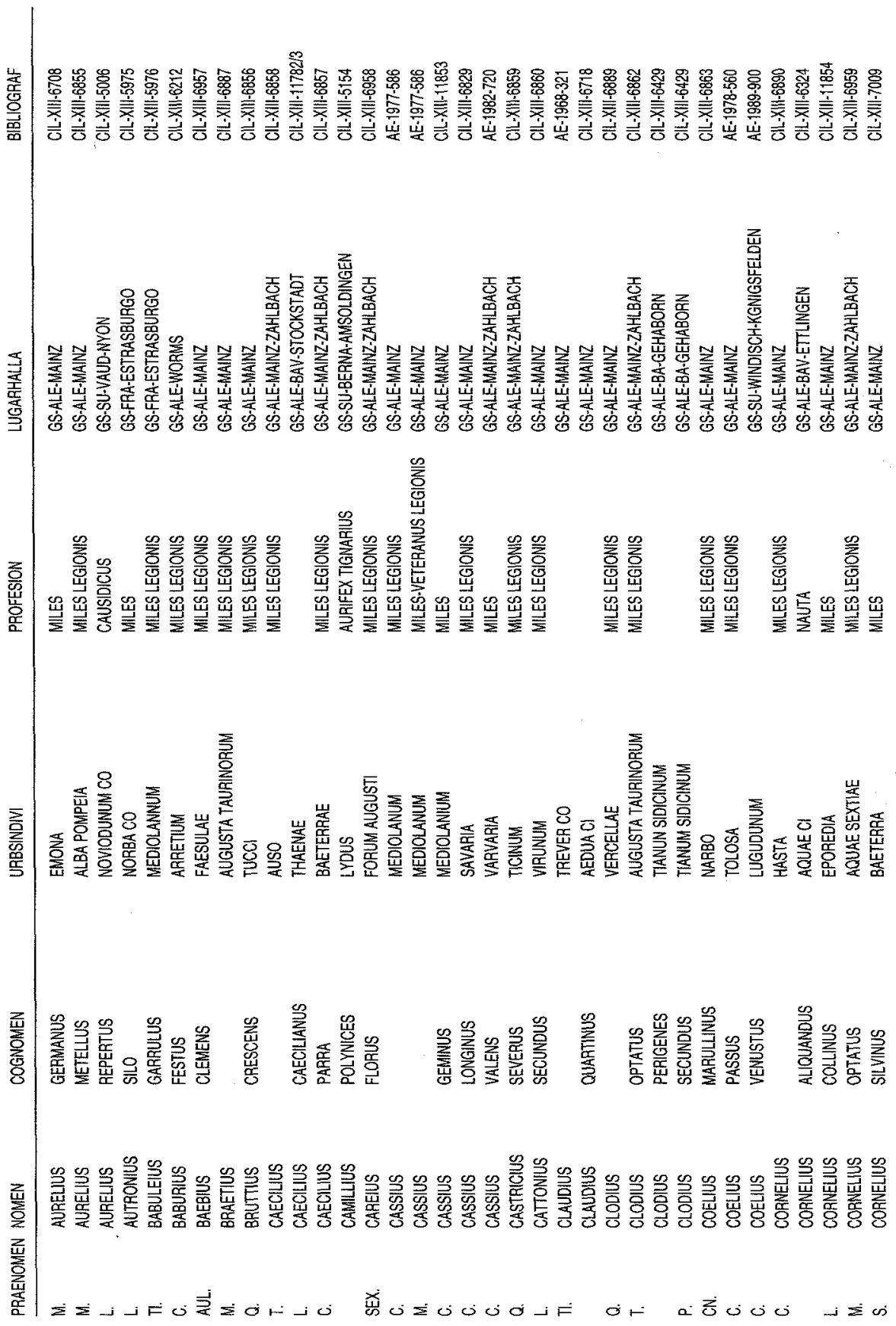




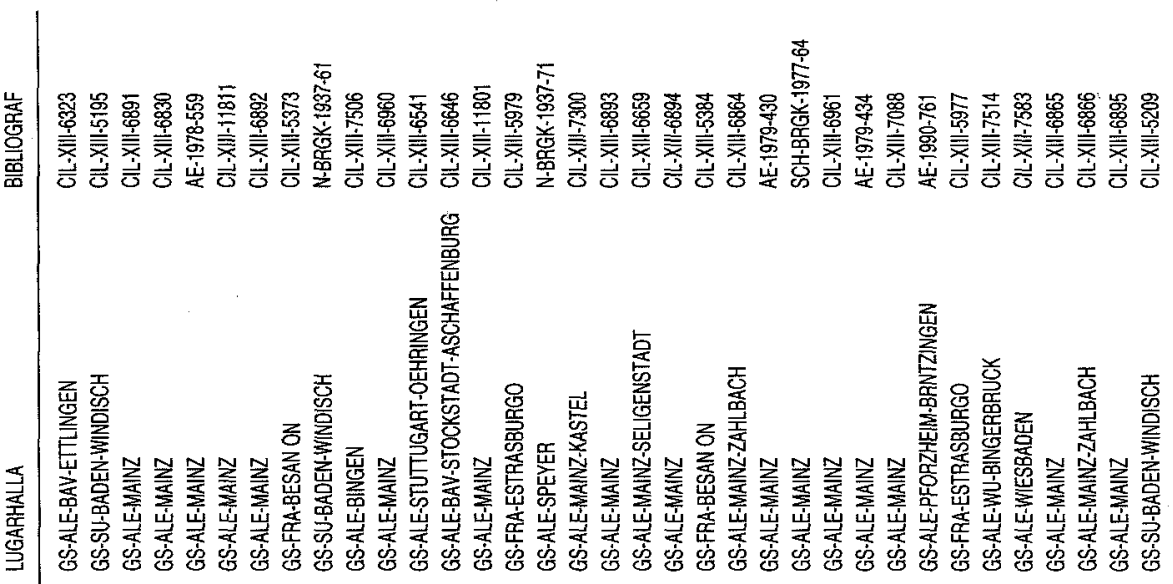

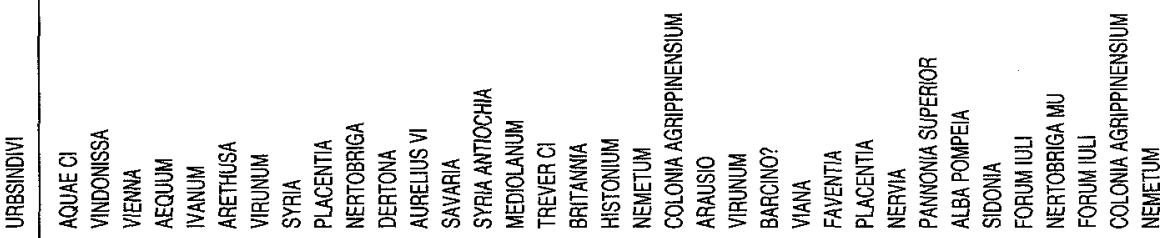

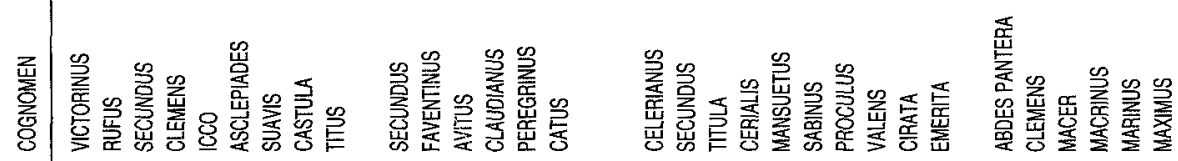

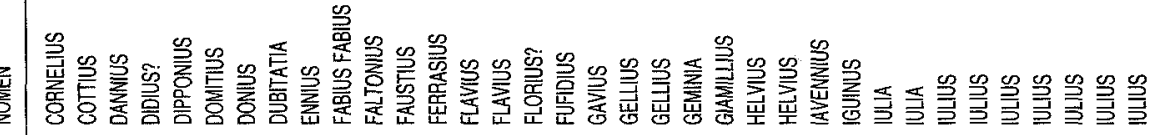




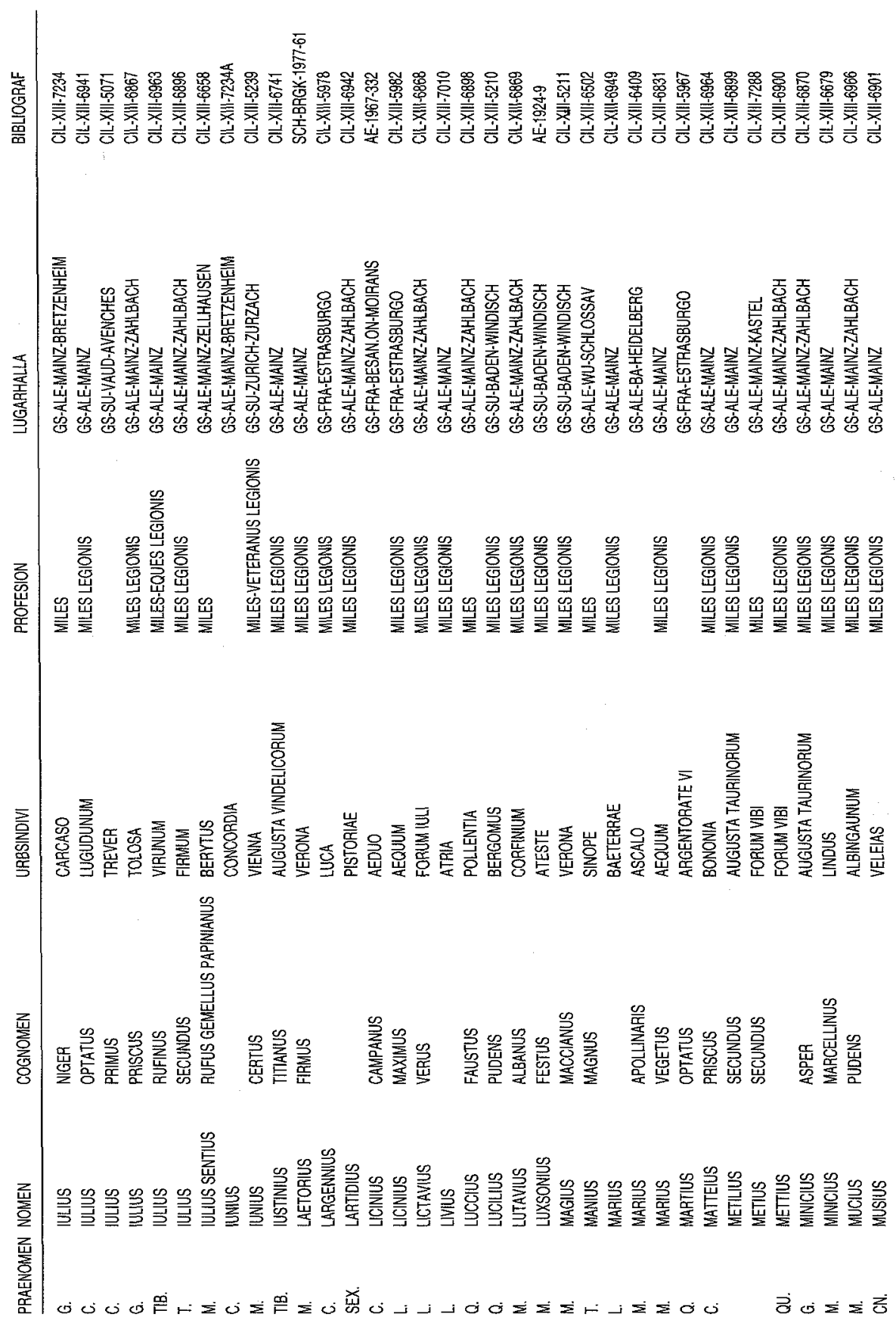




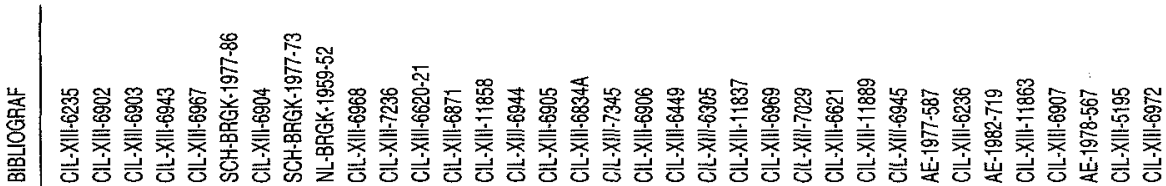

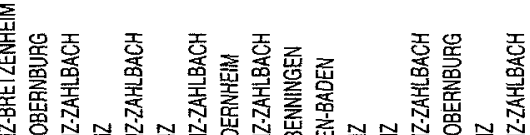

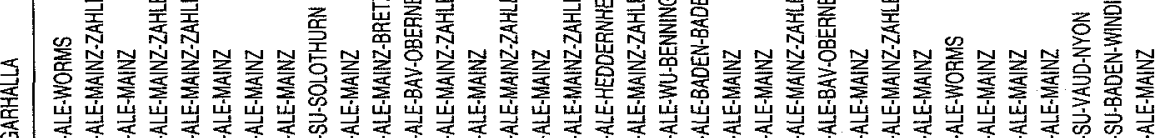

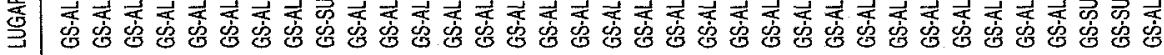

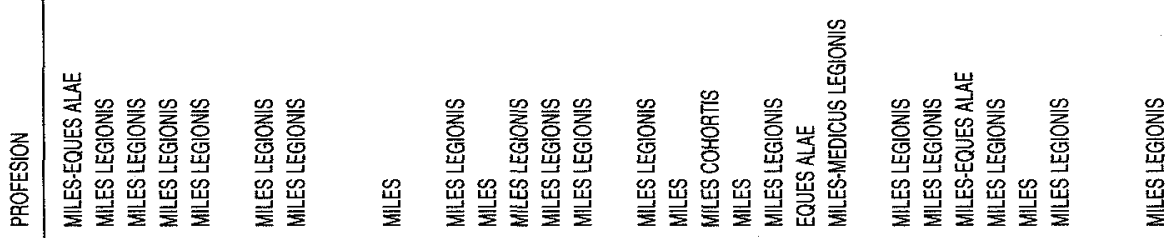

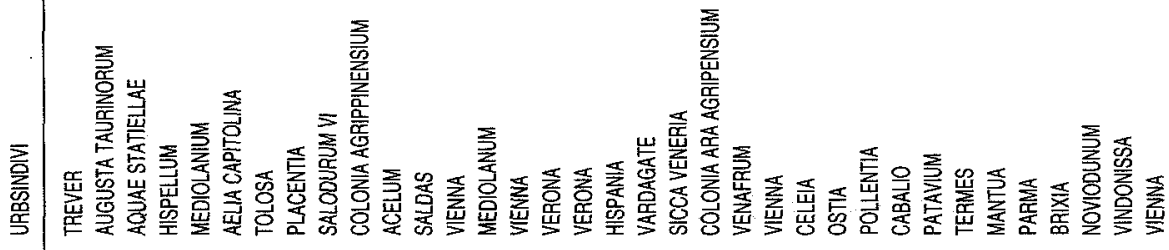

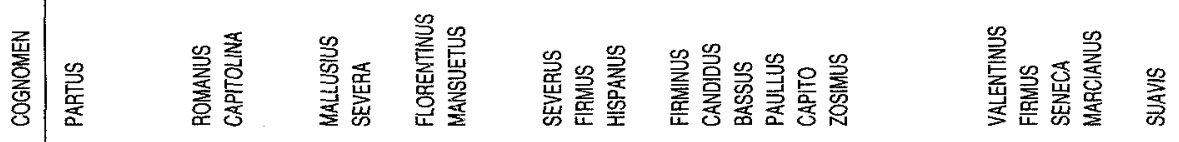

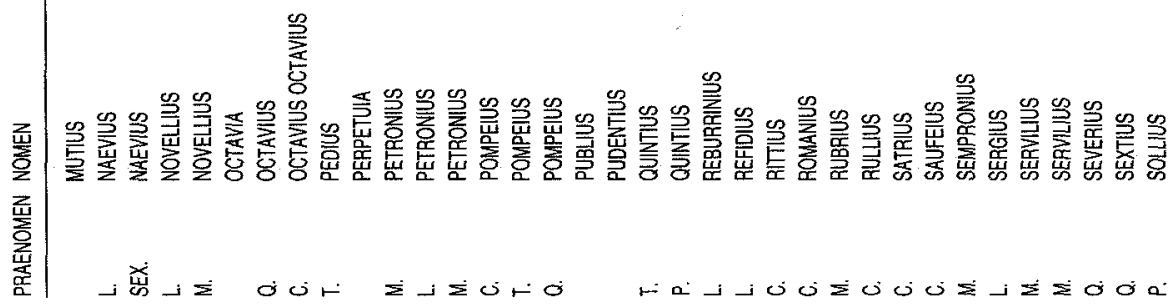




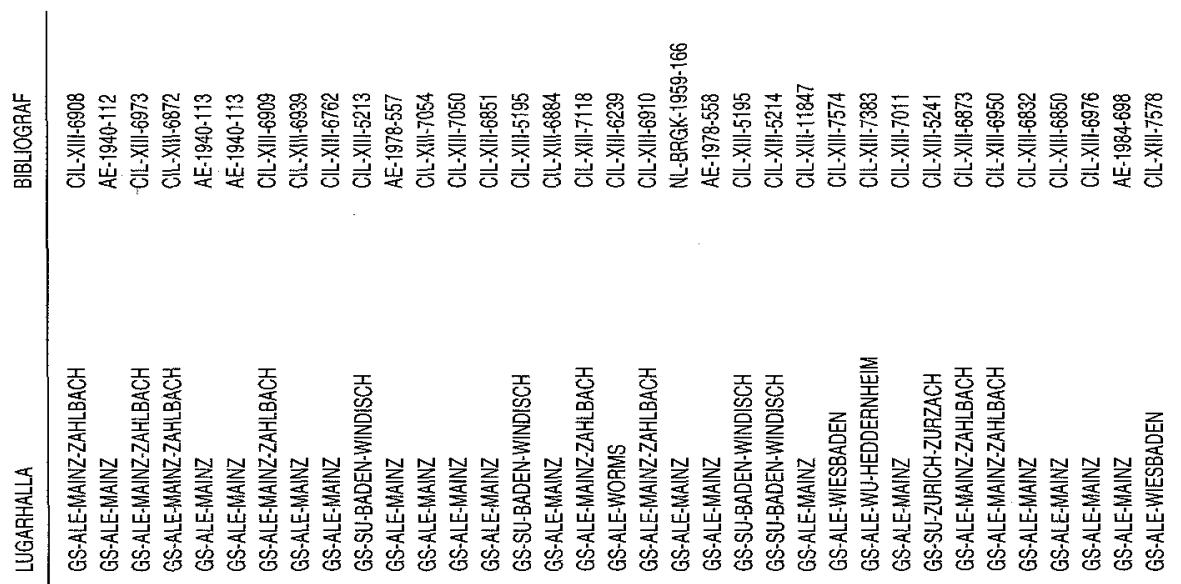

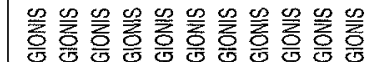

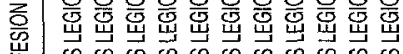

冚

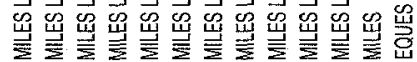

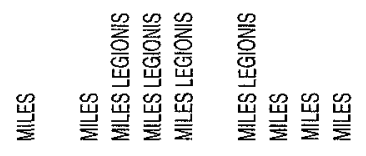

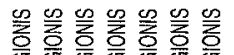

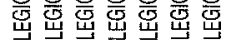

몸

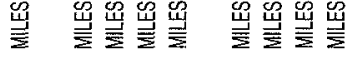

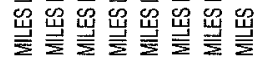

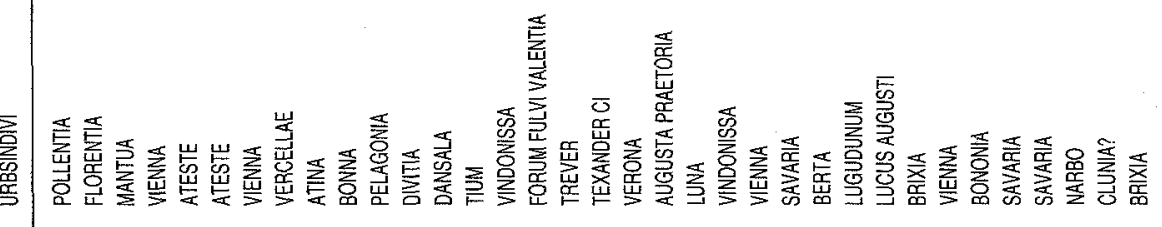

홓

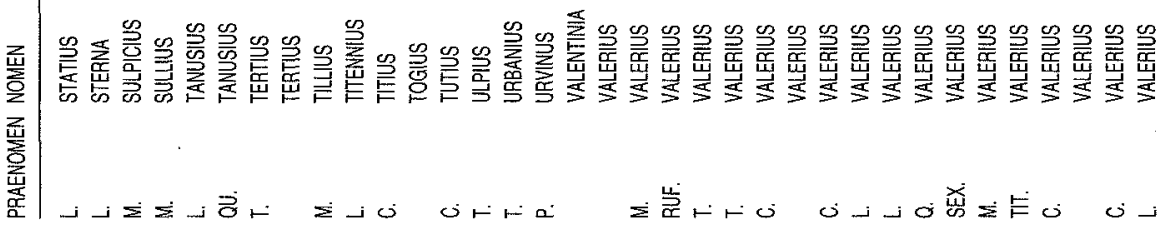




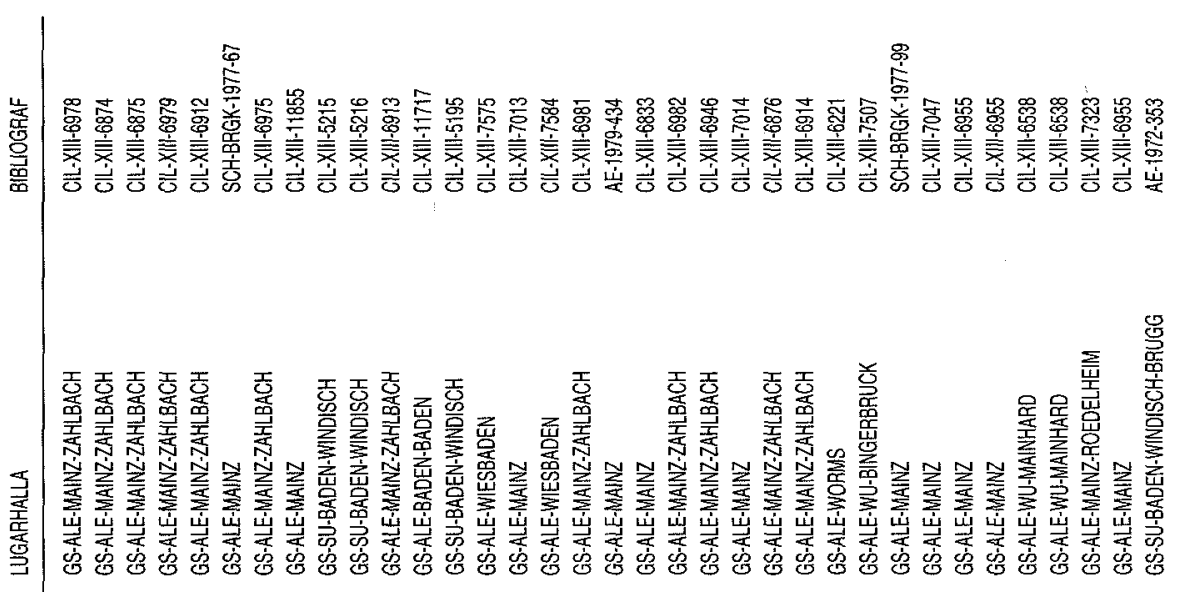

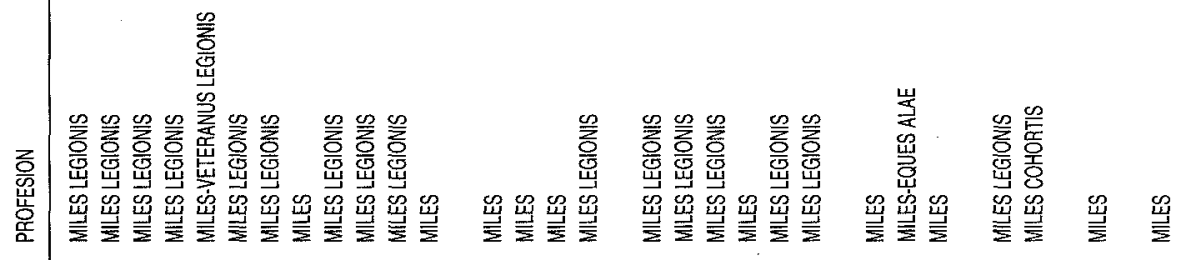

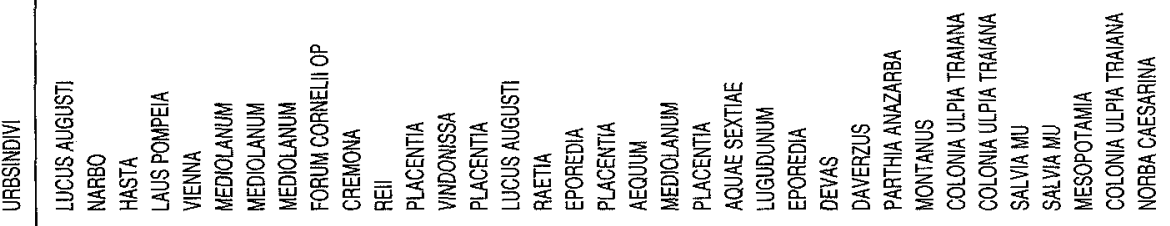

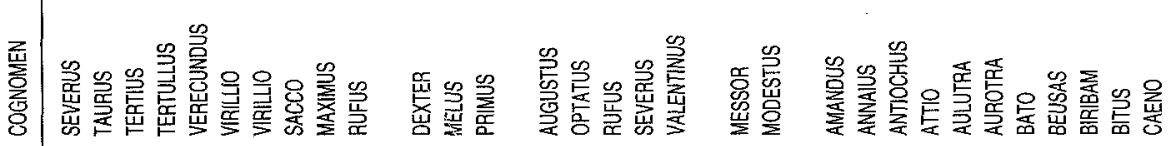

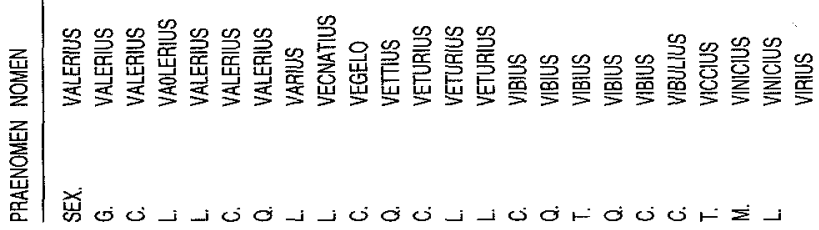




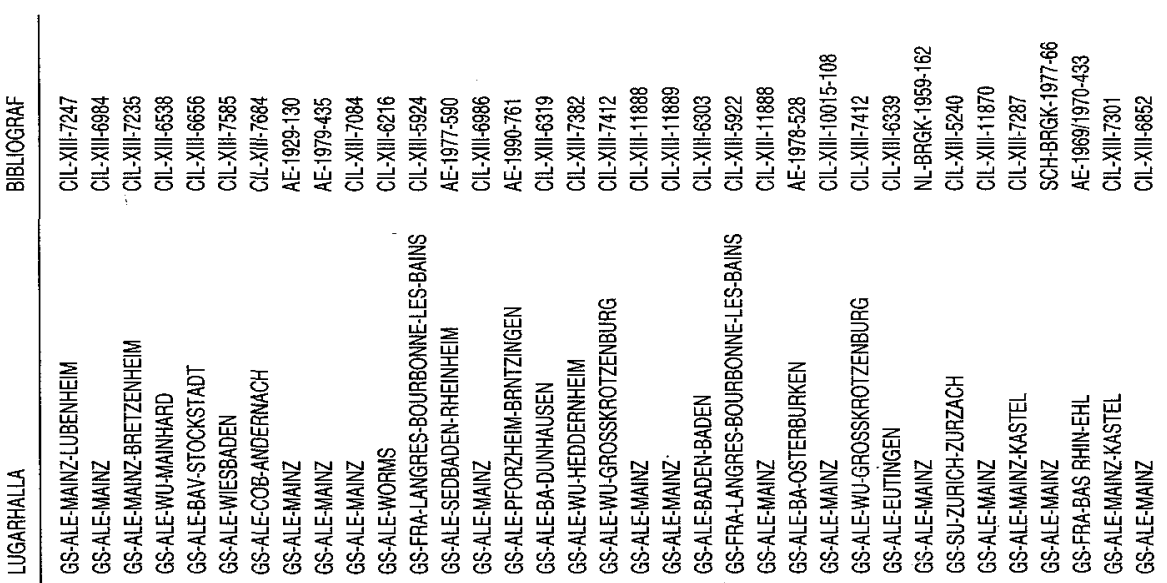

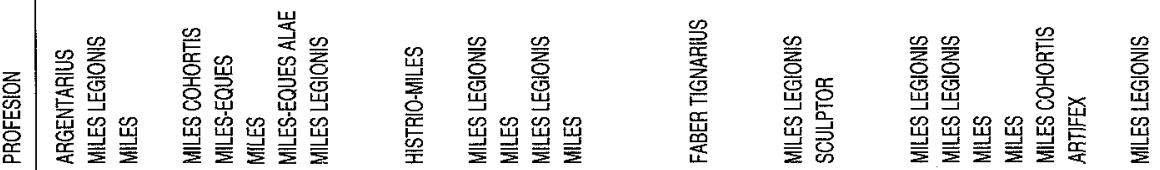

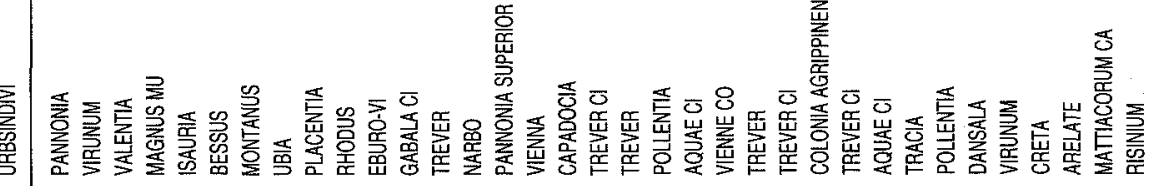

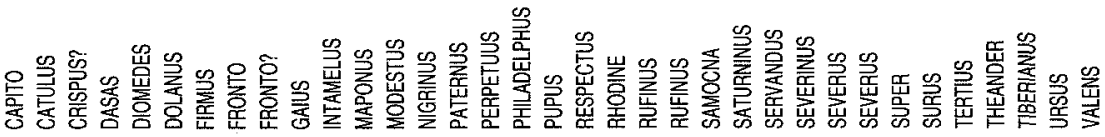




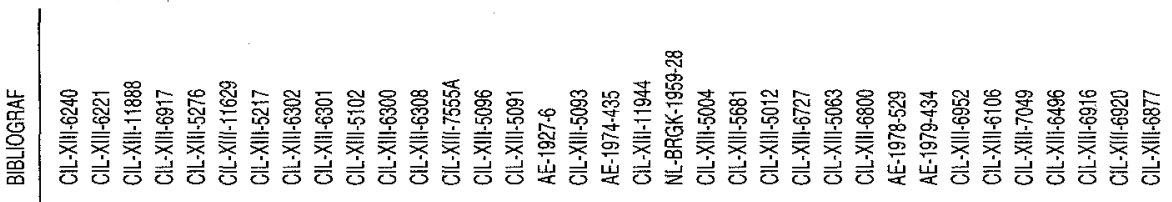

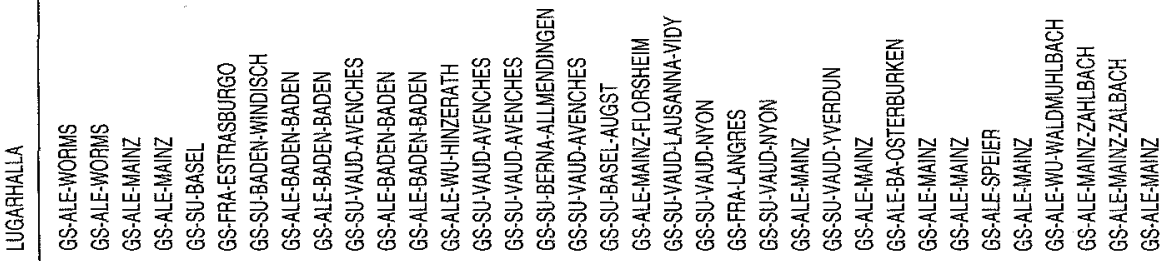

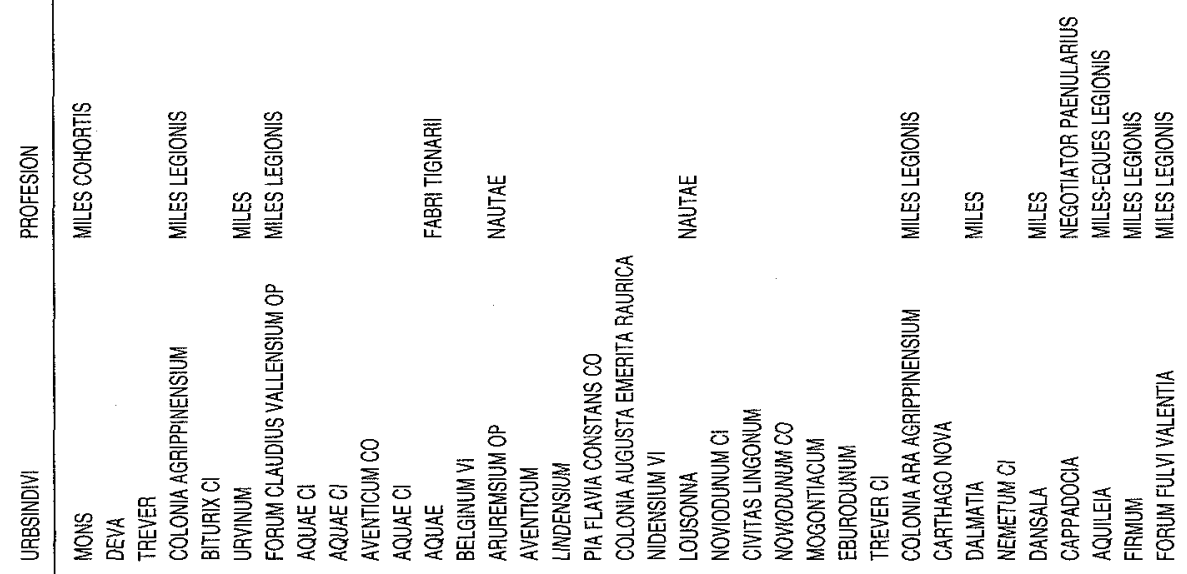

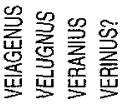




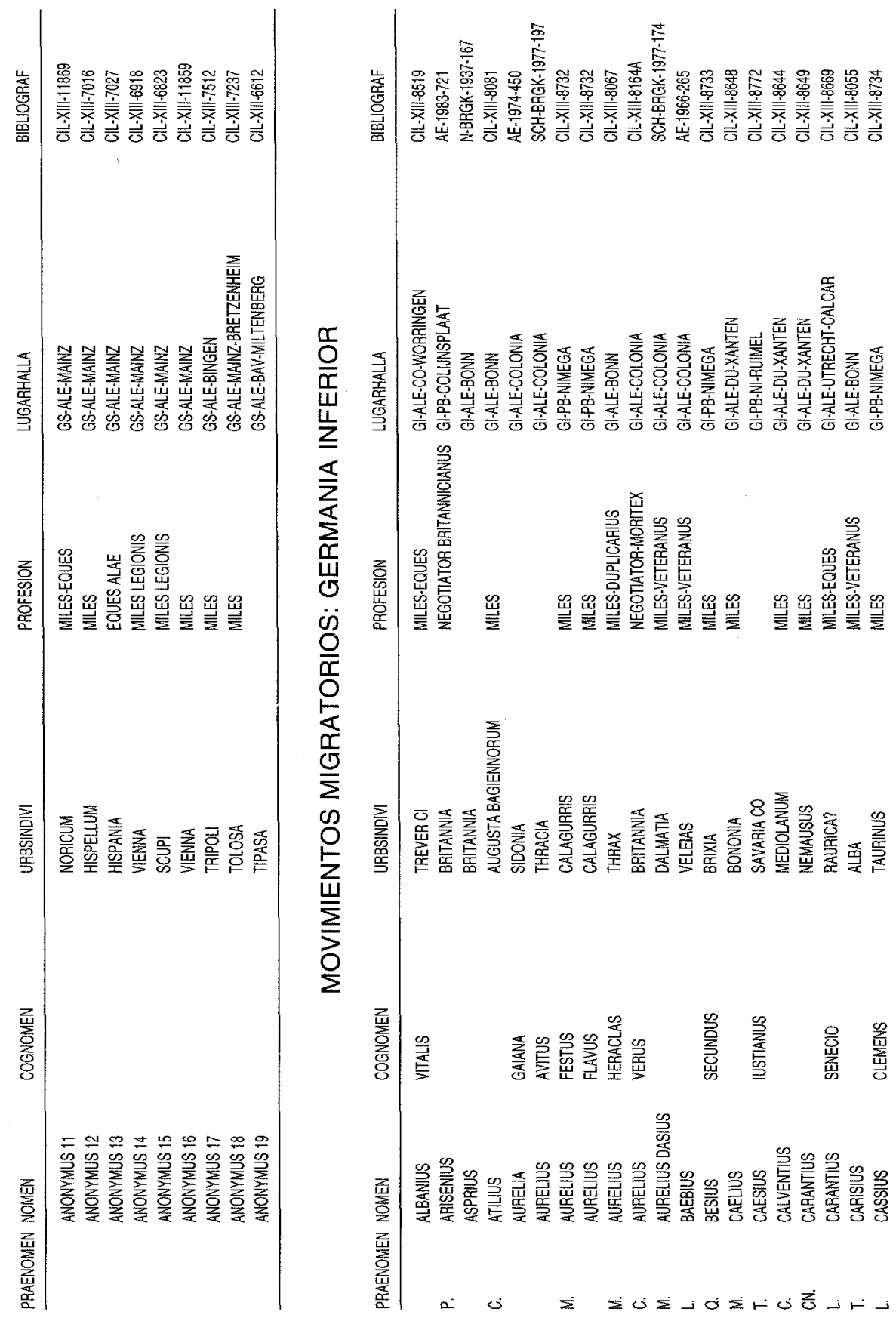




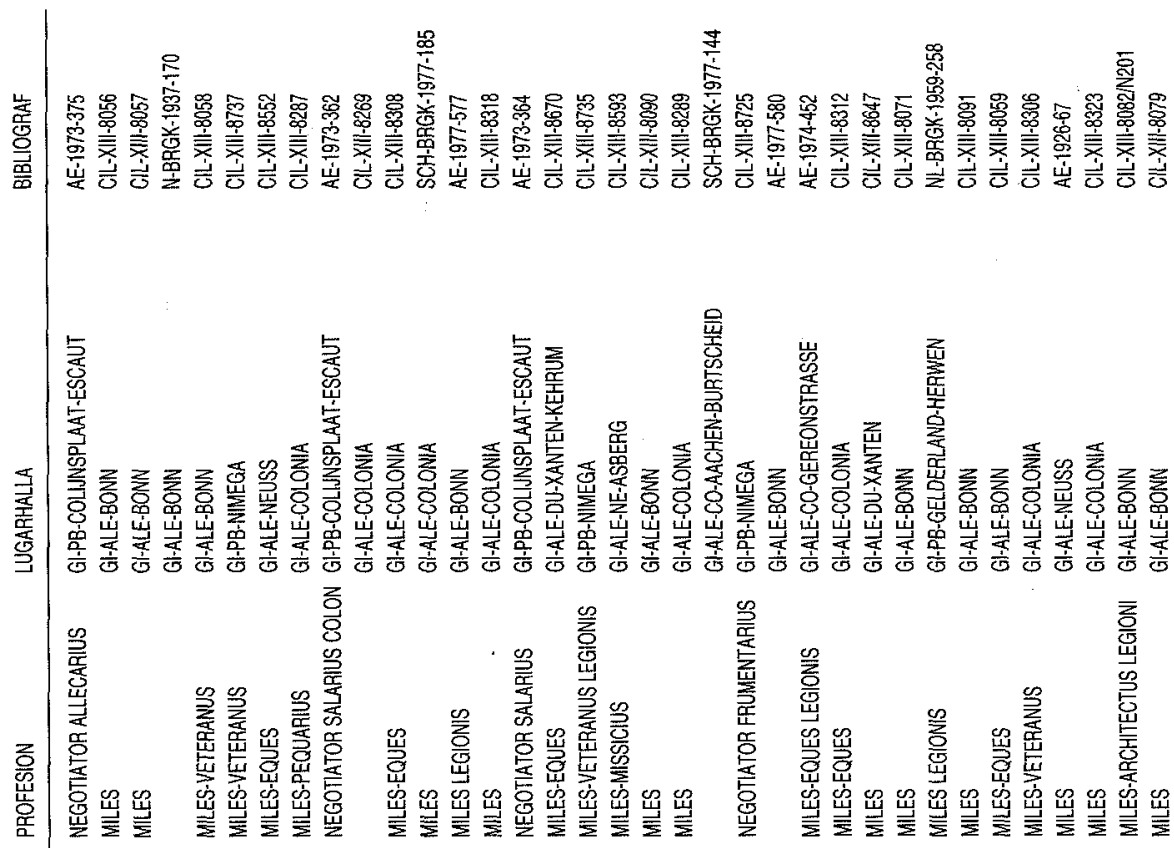

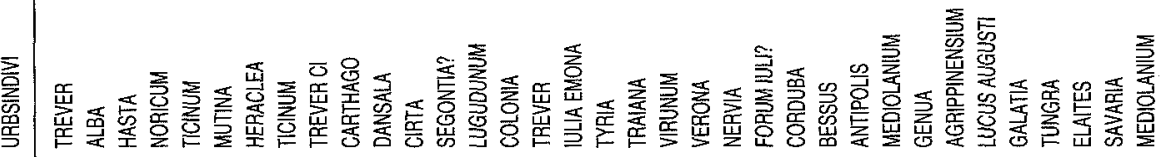

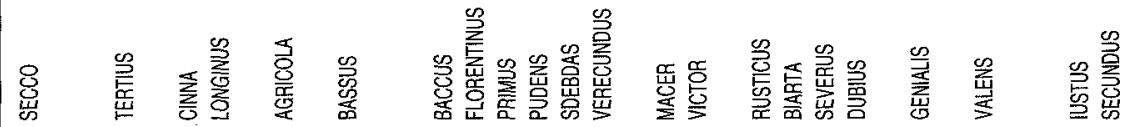

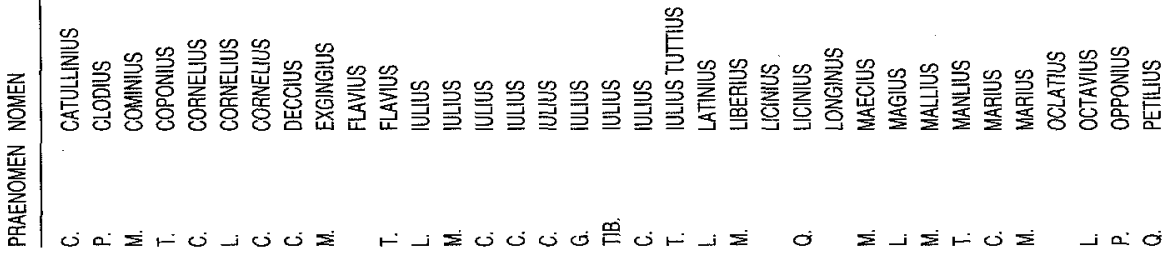




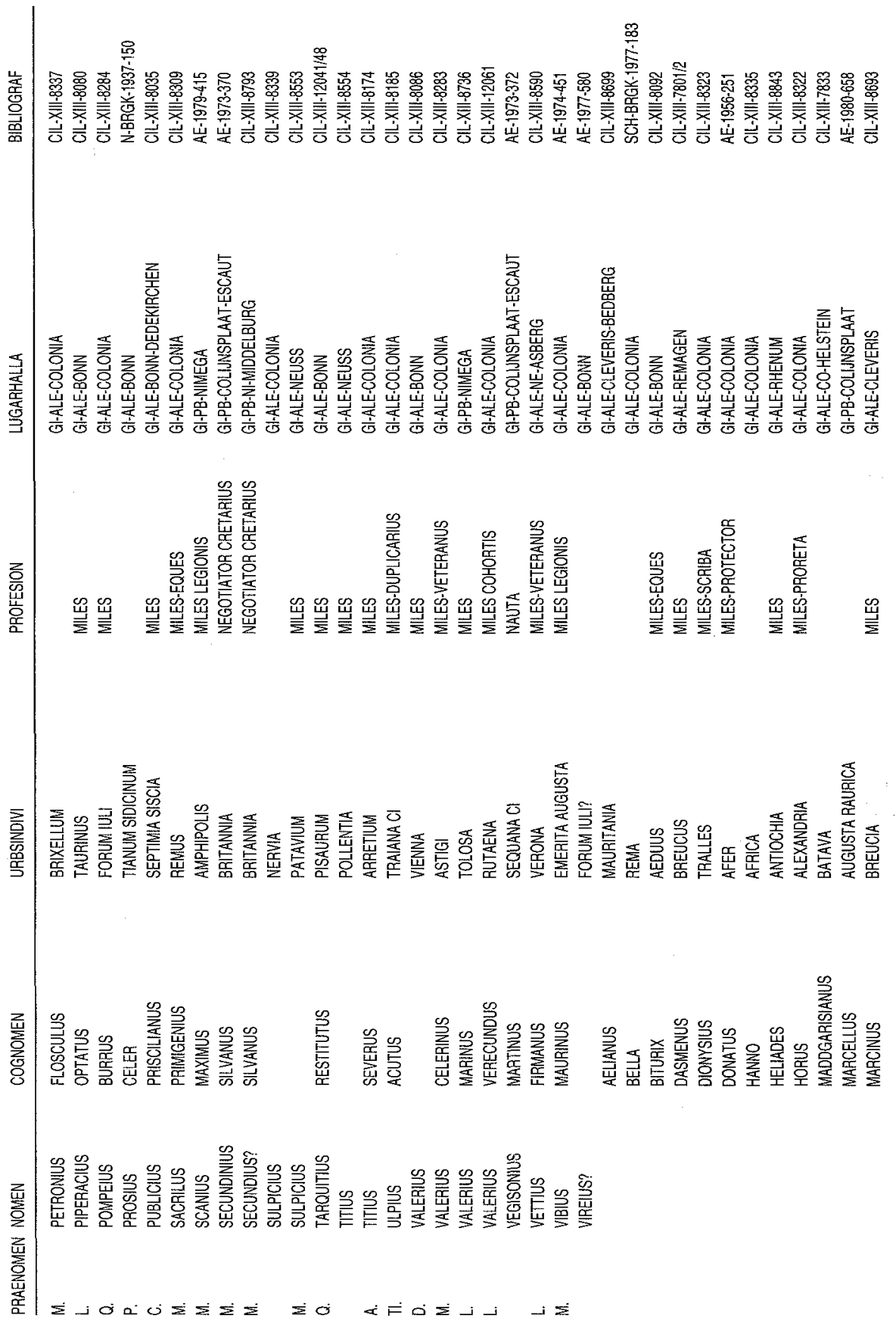




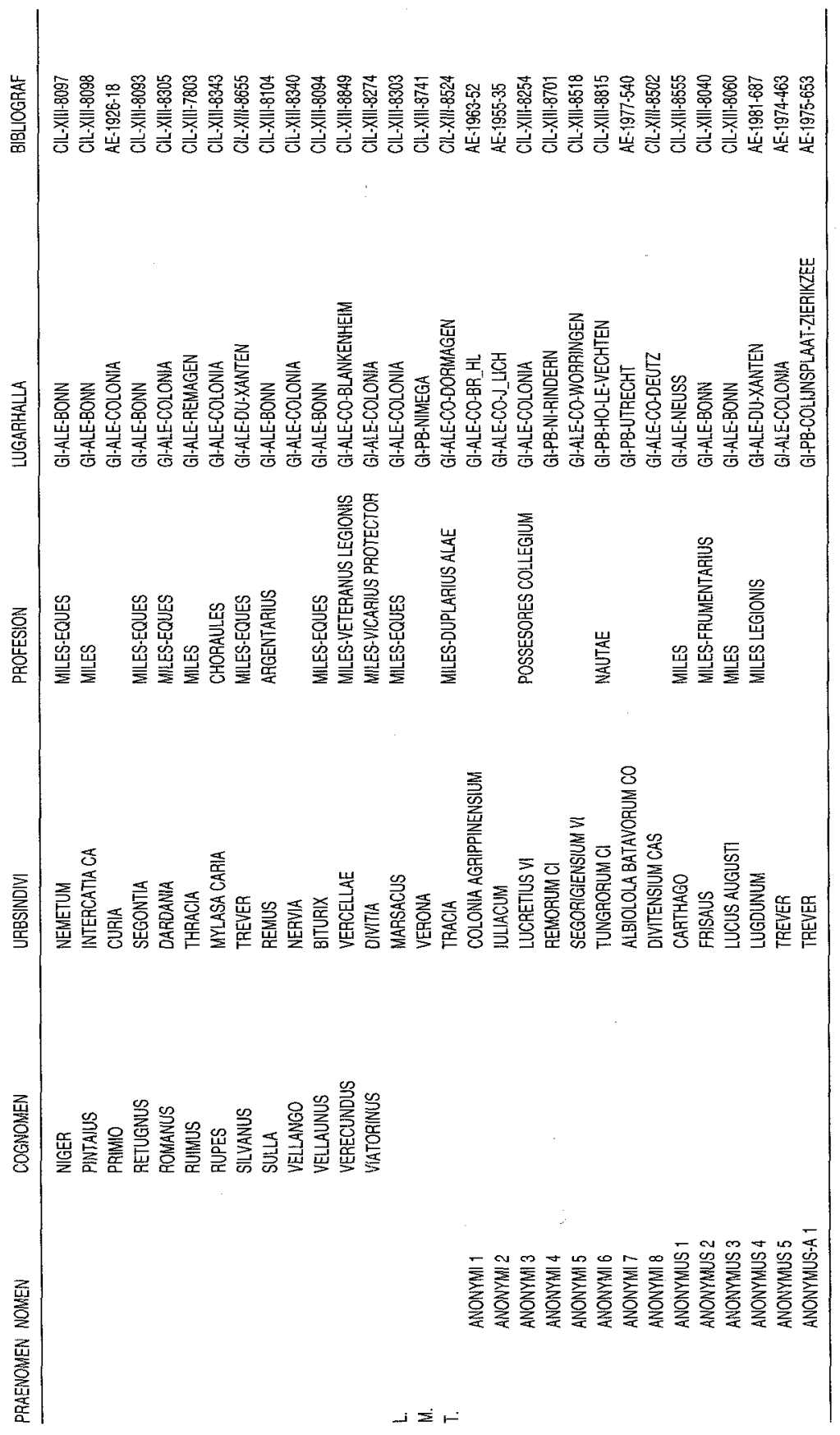

